\title{
eNeuro
}

Research Article: New Research / Sensory and Motor Systems

\section{Stimulus generalization in mice during Pavlovian eyeblink conditioning}

https://doi.org/10.1523/ENEURO.0400-21.2022

Cite as: eNeuro 2022; 10.1523/ENEURO.0400-21.2022

Received: 27 September 2021

Revised: 24 January 2022

Accepted: 15 February 2022

This Early Release article has been peer-reviewed and accepted, but has not been through the composition and copyediting processes. The final version may differ slightly in style or formatting and will contain links to any extended data.

Alerts: Sign up at www.eneuro.org/alerts to receive customized email alerts when the fully formatted version of this article is published.

Copyright (? 2022 Fiocchi et al.

This is an open-access article distributed under the terms of the Creative Commons Attribution 4.0 International license, which permits unrestricted use, distribution and reproduction in any medium provided that the original work is properly attributed. 
Title: Stimulus generalization in mice during Pavlovian eyeblink conditioning

Running title: Stimulus generalization in mice

Authors: F.R. Fiocchi ${ }^{1}$, S. Dijkhuizen ${ }^{1}$, S.K.E. Koekkoek ${ }^{1}$, C.I. De Zeeuw ${ }^{1,2}$, H.J. Boele ${ }^{1,3 *}$

Affiliations:

${ }^{1}$ Erasmus MC Rotterdam, Department of Neuroscience, Rotterdam, 3015 GD, The Netherlands

${ }^{2}$ Netherlands Institute for Neuroscience, Royal Dutch Academy of Arts \& Science (KNAW), 1105 BA, Amsterdam, The Netherlands

${ }^{3}$ Princeton Neuroscience Institute, Princeton, NJ 08540, USA

*Correspondence: h.boele@erasmusmc.nl

\section{Number of pages: 33}

Number of figures: 9

Number of tables: 5

Number of words abstract: 210

Number of words introduction: 664

Number of words discussion:2414

\section{Conflict of Interest:}

The authors declare no competing financial interest.

\section{Acknowledgements:}

H.J. Boele received financial funding from the European Research Council - Proof of Concept Grant (\#737619), The Netherlands Organization for Scientific Research - Veni ZonMW (\#91618112), and Erasmus MC Fellowship (\#106958). C.I. De Zeeuw received financial funding from the European Union's Horizon 2020 research and innovation program under the Marie Skłodowska-Curie grant agreement (\#722098), Medical NeuroDelta Programme, Topsector Life Sciences \& Health (Innovative Neurotechnology for Society or INTENSE), Albinism Vriendenfonds Netherlands Institute for Neuroscience, and European Research Council - Advanced Grant (\#294775). 
Here we investigate stimulus generalization in a cerebellar learning paradigm, called eyeblink conditioning. Mice were conditioned to close their eyes in response to a $10 \mathrm{kHz}$ tone by repeatedly pairing this tone with an air puff to the eye $250 \mathrm{~ms}$ after tone onset. After ten consecutive days of training, when mice showed reliable conditioned eyelid responses to the $10 \mathrm{kHz}$ tone, we started to expose them to tones with other frequencies, ranging from 2 to 20 $\mathrm{kHz}$. We found that mice had a strong generalization gradient, whereby the probability and amplitude of conditioned eyelid responses gradually decreases depending on the dissimilarity with the $10 \mathrm{kHz}$ tone. Tones with frequencies closest to $10 \mathrm{kHz}$ evoked the most and largest conditioned eyelid responses and each step away from the $10 \mathrm{kHz}$ tone resulted in fewer and smaller conditioned responses. In addition, we found that tones with lower frequencies resulted in conditioned responses that peaked earlier after tone onset compared to those to tones with higher frequencies. Together, our data show prominent generalization patterns in cerebellar learning. Since the known function of cerebellum is rapidly expanding from pure motor control to domains that include cognition, reward-learning, fear-learning, social function, and even addiction, our data implies generalization controlled by cerebellum in all these domains.

\section{Significance Statement:}

Conditioned stimuli that resemble each other will evoke a rather similar behavioral response. 57 Here, we investigate this phenomenon of stimulus generalization using Pavlovian eyeblink 58 conditioning to probe cerebellar function. Cerebellum is a brain structure whose known 59 function is rapidly expanding from pure motor control to domains that include cognition, 60 reward-learning, fear-learning, social function, and even addiction. Since we found a strong 61 generalization of the auditory stimulus in eyeblink conditioning, our data implies an 62 important role for generalization in motor and non-motor domains. 


\section{Introduction}

Given the advance of transgenics and optogenetics (Boyden, 2015; Deisseroth, 2011; Navabpour et al., 2020), mice have become increasingly a popular animal model to study mechanisms underlying cerebellar learning (Alba, 1994; Albergaria et al., 2018; Gao et al., 2016; Heiney et al., 2014; Kloth et al., 2015; Zhang et al., 2019). This also holds for Pavlovian eyeblink conditioning, a behavioral test that allows for wide variations in parameter space, including those of onset, duration and intensity of both conditional and unconditional stimuli (Alba, 1994; Chettih et al., 2011). Accordingly, experimental procedures for eyeblink conditioning in mice have been optimized over the last few years, evolving from EMG and MDMT to less invasive high-speed video recordings of the eyelids while the mouse is walking on a treadmill system (Albergaria et al., 2018; De Zeeuw \& Ten Brinke, 2015; Heiney et al., 2014; Koekkoek et al., 2002). Even so, some basic concepts of eyeblink conditioning, which have been studied quite extensively in humans and rabbits, have not yet been studied well in mice.

One of these concepts is called 'stimulus generalization'. Stimulus generalization is the phenomenon whereby a certain behavioral response is elicited by a stimulus other than the one that initially led to the acquisition of this specific response (Lashley \& Wade, 1946; Pavlov, 1927; Razran, 1949). Stimulus generalization plays a crucial role in our daily life behavior. Think for instance about how we, as a pedestrian, will immediately respond to the sound of any car horn when we are about to cross a road. Indeed in neuroscience, stimulus generalization has probably been most extensively studied in the context of Pavlovian fear conditioning (Bang et al., 2008; Dymond et al., 2015; Hovland, 1937; Lissek et al., 2008; Meulders \& Vlaeyen, 2013), showing that emotional and fight-or-flight responses can be easily triggered by stimuli other than the one used during acquisition training.

In the current study we employ Pavlovian eyeblink conditioning in mice to study the stimulus generalization of their responses that reflect motor memories. In the paradigm used in this study, mice were first trained to close their eyes in response to a tone with a frequency of $10 \mathrm{kHz}$, by repeatedly pairing this $10 \mathrm{kHz}$ tone (conditional stimulus, CS) with a mild air puff to the eye (unconditional stimulus, US). After ten consecutive daily training sessions, which is sufficient for most mice to reliably show eyelid conditioned responses (CRs) to the $10 \mathrm{kHz}$ tone, we suddenly introduced alternative tones with frequencies ranging between 2-8 and $12-20 \mathrm{kHz}$. In contrast to the $10 \mathrm{kHz}$ tone, these tones were never reinforced with the aversive air puff. In line with previous work (Dymond et al., 2015), we will use in this paper the term 'conditional stimulus or CS' to refer to the $10 \mathrm{kHz}$ tone that was reinforced with the air puff US, and the term 'generalization stimulus (GS)' for the other tones, varying between $2-8$ and $12-20 \mathrm{kHz}$, that were never reinforced with the air puff US. Thus, we set out to investigate to what extent eyeblink CRs are elicited by these GSs in mice that do show reliable CRs to the CS.

The advantage of eyeblink conditioning is that it does not only permit robust variations in the stimulus parameters, but also that it reveals the CR probability as well as quantification of the size (or amplitude) and timing of the CRs. Eyeblink CRs are not simple reflexive blinks in response to the tone, but precisely timed responses, the amplitude of which increase gradually over the course of training (Boele et al., 2016). The adaptive timing of eyeblink CRs depends on the interval between CS and US onset: after conditioning the eye will be maximally closed just before the moment that the air puff (i.e., US) will be delivered. Thus, in this study we quantified CR probability, CR amplitude, and CR timing as a function of tone frequency, allowing us to investigate to what extent these different parameters are subject to the stimulus generalization principle. 


\section{Methods}

\section{Subjects}

We used 14 wild-type C57B1/6 mice, 7 of which were male and 7 were female. Mice were between 11-16 weeks old at the start of the experiment. All mice were housed individually during the experiment with food and water ad libitum in a 12:12 light/dark cycle. Experiments were performed during the light phase. All experiments were performed in accordance with the European Communities Council Directive. Protocols were reviewed and approved by the Erasmus Laboratory Animal Science Center (work protocol nr. 15-273-138; project license nr. AVD101002015273)

\section{Auditory Brainstem Responses}

Since $\mathrm{C} 57 \mathrm{~B} 1 / 6$ mice are prone for developing hearing problems, we recorded prior to the start of eyeblink conditioning training the auditory brainstem responses (ABRs) to obtain hearing level thresholds. Mice were anesthetized with a ketamine/xylazine mixture at a dose of $100 / 10 \mathrm{mg} / \mathrm{kg}$ body weight, administered intraperitoneally (ketamine: Alfasan, Woerden, NL; xylazine: Sedazine ${ }^{\circledR}$, AST Farma, Oudewater, NL). After this, they were placed in a soundand light-attenuated box with the ears at a distance of $4 \mathrm{~cm}$ from a frontally placed loudspeaker. Needle electrodes were positioned subdermal at the base of both pinnae, the external part of the ear. The reference electrode was placed at the vertex, the upper surface of the head, and a ground electrode on the lower back. Stimuli were generated and presented by a RZb Multi I/O Processor (TuckerDavis Technologies) and BioSigRZ software. Responses were recorded using Medusa DA4PA, 4-dh Preamp device. Responses with amplitudes larger than $30 \mu \mathrm{V}$ were considered as artefacts and therefore excluded from further analysis. Hearing level thresholds were measured at 4, 8, 16 and $32 \mathrm{kHz}$ (Willott, 2006). Thresholds were defined as the lowest sound pressure level (SPL) at which a reproducible response (i.e., peak in the ABR trace) was still detectable. Since our main aim was to establish that mice could detect the tones used in our behavioral training paradigm and not to establish definite age and mouse species dependent absolute hearing thresholds, we performed our ABR recordings under anesthesia since it is technically less complicated. One should keep in mind, however, that ABR responses under ketamine/xylazine anesthesia, although it is a standard procedure in mice (Huang et al., 1995; Ingham et al., 2011; Willott, 2006), are generally weaker compared to those recorded in awake animals (van Looij et al., 2004). After the ABR recordings, which took about 20-30 minutes per animal, mice were injected with atipamezole (Antisedan ${ }^{\circledR}$, Orion Pharam, Finland) (10 mg/kg body weight, administered intraperitoneal) for the reversal of xylazine.

\section{Surgery}

After ABR recordings, mice had two days of recovery before they underwent surgery. Mice were anesthetized with 2\% isoflurane (vaporizer for Isoflurane Anesthetic Model100 Vaporizer, Forane ${ }^{\circledR}$, Surgivet) and body temperature was kept constant at $\sim 37$ degrees Celsius (DC Temperature controller, FHC). After fixation in a standard mouse stereotaxic alignment system (Stoelting) and under sterile conditions, the scalp was incised $(\sim 10 \mathrm{~mm})$ to expose the skull. Membranous tissue was cleared and the bone was prepared with Optibond $^{\mathrm{TM}}$ FL (All-in-one bonding agent Kerr®, Salerno, Italy). A small brass pedestal with a square magnet on top was attached to the skull with a dental composite (Charisma - Mitsui Chemical Group, Kulzer, Germany), using an xyz manipulator, allowing for fixation to a head bar at right angles during experiments. After surgery mice recovered under a heating lamp for at least 20 minutes, until they were fully awake. They were given post-operative 
analgesic (Rimadyl® Cattle, Cappelle a/d Ijssel, NL) on the following day. Mice had three days to fully recover, before eyeblink conditioning habituation training started.

\section{Eyeblink conditioning - apparatus}

All behavioral experiments were conducted in custom built sound- and light- attenuating boxes. Mice were placed head-fixed on top of a cylindrical treadmill on which they were allowed to walk freely (Figure 1A) (Boele et al., 2018; Heiney et al., 2014). The treadmill consisted of a foam roller (diameter, $\pm 15 \mathrm{~cm}$; width, $+/-12 \mathrm{~cm}$; Exervo, TeraNova EVA) with a horizontal metal rod through the axis that was connected with a ball bearing construction to two solid vertical metal poles. A horizontal messing bar was fixated to the same vertical poles at 3 to $5 \mathrm{~cm}$ above the treadmill. Mice were head-fixed to the bar with the use of a screw, allowing the magnet on top of the pedestal to perfectly dovetail another magnet with opposite polarity in the middle of the horizontal messing bar in the exact point of fixation, thereby ensuring easy fixation and perfect head stability (Figure 1A) (Boele et al., 2018; Chettih et al., 2011; Heiney et al., 2014). The CS was a $280 \mathrm{~ms}$ tone with a frequency of $10 \mathrm{kHz}$ with a $25 \mathrm{~ms}$ ramp/decay time. The US consisted of a $30 \mathrm{~ms}$ duration mild corneal air puff, which was controlled by a VHS P/P solenoid valve (Lohm rate, 4750 Lohms; Internal volume, 30 $\mu \mathrm{L}$, The Lee Company®, Westbrook, US) and delivered via a $27.5 \mathrm{~mm}$ gauge needle that was perpendicularly positioned at about $5 \mathrm{~mm}$ from the center of the left cornea. The back pressure on the solenoid valve was set at $30 \mathrm{psi}$. We used an interstimulus interval of $250 \mathrm{~ms}$ and an intertrial interval of 8-12 seconds. Eyelid movements were recorded using a highspeed video camera (333 fps, Basler® a cA640-750u m ID: 106748-15, Germany). Stimulus control and data acquisition were done with National Instruments hardware. All experiments were performed at approximately the same time of the day by the same experimenter.

\section{Eyeblink conditioning - habituation to eyeblink conditioning apparatus}

Mice were head-fixed on the head bar and allowed to walk on the treadmill for 20-30 minutes per day for 2 days without any stimuli in order to get them acquainted with the eyeblink setup.

\section{Eyeblink conditioning - baseline measurements to find the proper tone threshold for each animal}

After the two days of habituation, we measured the sensitivity of each mouse for the tone CS $(10 \mathrm{kHz})$ and tone GSs (ranging from $2-8$ and $12-20 \mathrm{kHz}$ in steps of $2 \mathrm{kHz}$ ). Since the responsiveness of an individual mouse to auditory stimuli can slightly vary from day to day and since we were testing ten different tone frequencies and did not want to present too many trials during a baseline session, we repeated this measurement for ten consecutive days for each animal (30 minutes each day), until we found for each animal the proper sound pressure levels (SPL in dB) for each tone frequency (Figure 3A, 2B). Each baseline session consisted of 2 blocks of 10 tone-only trials and 1 US-only trial each, and thus had 2 tone-only trials of each tone frequency for each session.

As a behavioral readout for the tone sensitivity, we used the eyelid component of the auditory startle reflex (Boele et al., 2010). This startle response, sometimes referred to as alpha response, was quantified using the velocity signals (1st derivative of position signal) (Figure 3C). An eyelid response was considered as a startle response if there was a peak in the velocity signal between 30 to 80 -ms after CS onset that was larger than 3 standard deviations of the $500 \mathrm{~ms}$ baseline period and larger than an arbitrary threshold set at 0.00025 (Figure 3B, D). We considered the potential effect of 'latent inhibition', which is the phenomenon whereby it takes longer to get conditioned to a familiar stimulus (i.e., a tone that one has heard many times) than to novel stimulus (i.e., a new tone). Therefore, all animals 
received the exact same number of CS-only trials during baseline, so that the novelty level of the tone was equal for all animals.

\section{Eyeblink conditioning - Acquisition training sessions}

Mice were trained for 10 consecutive days (40 minutes/day). Each daily session was composed of 20 blocks of 12 trials each. Each block consisted of 1 US-only trial, 10 paired (CS-US with an interstimulus interval, ISI of 250-ms) trials and 1 CS-only trial (Figure 1B, C). Trials were semi-randomly distributed, whereby a CS-only trial was always immediately preceded by at least 2 paired CS-US trials.

\section{Eyeblink conditioning - Generalization test sessions}

The 10 days of acquisition training were followed by 7 generalization test sessions, during which the GSs were presented in addition to the CS. Each daily generalization test session was composed of 8 blocks of 31 trials each, including 20 paired CS-US trials, 1 US-only, and 10 tone (CS or GS) only trials (Figure 1B). Since the ratio of paired CS-US to CS/GS only trial changed significantly, we carefully checked day-by-day whether there was any extinction of eyeblink CRs. Since it is known that the probability of a CR is lower in a trial that is preceded by a trial wherein the tone was not reinforced (Najafi \& Medina, 2020), in our experimental design a tone only trial (CS only or GS only) was always immediately preceded by two paired CS-US trials.

\section{Eyeblink conditioning - Data analysis}

Individual eyeblink traces were analyzed with a custom-written MATLAB script (R2018a, Mathworks). First, the $2000 \mathrm{~ms}$ eyeblink traces were imported from the MySQL database into MATLAB. The trials were aligned at zero for the 500-ms pre-CS baselines. Trials with significant activity in the $500 \mathrm{~ms}$ pre-CS period (> 7-times the interquartile range) were regarded as invalid and disregarded for further analysis. The eyelid signal was min-max normalized so that a fully open eye corresponded with a value of 0 and a fully closed eye with a value of 1 . This normalization was achieved by aligning the $500 \mathrm{~ms}$ pre-CS baselines of all traces and dividing each trace by the averaged UR value that was calculated over all eyelid traces in US only trials for one session. The normalized eyelid closure amplitude was expressed as fraction eyelid closure or FEC.

In our analysis we only included CS-only trials, since these trials show the full kinetic profile of the eyelid response. In valid normalized CS-only trials, eyelid responses were considered as a CR if the maximum amplitude was larger than 0.05 in the interval between 100-500 ms after CS onset and the presence of a positive slope in the 150-ms before the time point where the US would have been delivered (US is omitted in CS-only trials). For each session for each mouse, we calculated the percentage of trials in which a CR was present, which we will refer to as 'CR percentage'. In addition, we determined for each trial the maximum eyelid closure between 100 and $500 \mathrm{~ms}$ after CS onset, which we will refer to as 'Eye closure - all trials'. Similarly, we calculated the maximum eyelid closure between 100 and $500 \mathrm{~ms}$ after CS onset in trials wherein a CR was present based on the criteria described above, which we will refer to as 'Eye closure - CR trials'. CR adaptive timing was investigated by calculating the latency to the onset of the CR relative to CS onset, referred to as 'Latency to CR onset', and the latency to maximum eye closure relative to CS onset, referred to as 'Latency to CR peak'. Latency to CR onset and latency to CR peak were only calculated in trials wherein a CR was present. Latency to CR onset was only calculated for trials wherein no alpha startle response was present.

Statistical analysis was done using multilevel linear mixed-effects (LME) models in R Studio (code available upon request). LMEs have several major advantages over standard 
262 parametric and non-parametric tests (Aarts et al., 2014; Schielzeth et al., 2020), as they are 263 more robust to violations of normality assumptions, which is often the case in biological data 264 samples. Moreover, use of LME models are able to accommodate the nested structure of our 265 data (i.e., trial nested within session, session nested within animal, animal nested within 266 group). Finally, LME models are objectively better at handling missing data points than 267 repeated measures analysis of variance (ANOVA) models and do not require 268 homoscedasticity as an inherent assumption. In our LME, we used session and tone 269 frequency as fixed effects, and mouse as a random effect. Goodness of fit model comparison 270 was determined by evaluating log likelihood ratio, BIC, and AIC values. The distribution of 271 residuals was inspected visually by plotting the quantiles of standard normal versus 272 standardized residuals (i.e., Q-Q plots). Correction for multiple comparisons was achieved, 273 using false-discovery rate (FDR). Data were considered as statistically significant if the 274 corrected p-value was smaller than 0.05 . 


\section{Results}

We used eyeblink conditioning to test stimulus generalization in mice that were conditioned using a $10 \mathrm{kHz}$ tone. Before we started the eyeblink conditioning acquisition training, we carefully measured the sensitivity of each mouse to the specific tones used during the experiment.

\section{Auditory brainstem and auditory startle responses}

Some mouse strains, including the popular C57B1/6 mouse strain, are susceptible to agerelated hearing loss. On the other end, mice in general are anxious prey animals that are very sensitive to sounds and easily startle (Dent et al., 2018; King et al., 2015; Turner et al., 2005). To this end, we tested both auditory brainstem responses (ABRs) and auditory startle responses in the mice prior to the start of the training. ABRs were measured in mice at the age of 9 weeks after birth. We followed the standardized protocol during which clicks were presented at 4, 8, 16, and $32 \mathrm{kHz}$ (Akil et al., 2016; Willott, 2006). At the lowest frequency of $4 \mathrm{kHz}$, a sound pressure level of $53 \mathrm{~dB}$ was needed to elicit a reliable ABR peak (Figure 2A). ABR peaks were elicited with the lowest sound pressure level of $23 \mathrm{~dB}$ at a frequency of 16 $\mathrm{kHz}$. Our results are in line with previous work testing ABRs in various mouse strains, including C57B1/6J, at roughly the same age range (Ison et al., 2007; Zheng et al., 1999). Since we found recognizable ABR peaks in the entire range of $4-32 \mathrm{kHz}$, and since our findings are in line with these previous reports in mice (Heffner \& Heffner, 2007; Reynolds et al., 2010), we conclude that hearing was intact in our animals.

Next, we established for each mouse the auditory startle response threshold. One component of the auditory startle response is a quick, partial, eyelid closure with a latency to peak of $\sim 50 \mathrm{~ms}$. Sometimes this alpha startle is followed by a beta startle, or short-latency response (SLR), which has a latency to peak of $\sim 100 \mathrm{~ms}$, and these beta startles can easily mask and sometimes even mimic cerebellar CRs. For this reason, we carefully determined at each tone (CS and GS) frequency for each mouse the SPL that was just sufficient to elicit a very small alpha startle response, but absolutely no beta startle (Boele et al., 2010). The sound frequencies used ranged from 2 to $20 \mathrm{kHz}$ in steps of $2 \mathrm{kHz}$; all stimuli had the same duration and ramp/decay pattern as those of the CS and GSs. Importantly, during the baseline measurement, these tones were never reinforced with an eye puff US. The baseline sessions were repeated for ten days, each day consisting of 20 trials, which was necessary to find a proper sound pressure level for each frequency and for each animal. To avoid the potentially differentiating effect of latent inhibition (Lubow, 1973; Lubow \& Moore, 1959) between animals, all mice received the exact same amount of tone-only trials during the baseline session.

Responses to tone-only trials at different tone frequencies for the last baseline session revealed that there was considerable variation in sound sensitivity between mice (Figure 2B). However, response thresholds for different frequencies within each mouse looked quite uniform (Figure 2B). In line with the ABR measurements, and in agreement with previous work (Heffner \& Heffner, 2007; Reynolds et al., 2010), we found that mice trended to be more sensitive, i.e., startled more easily at higher tone frequencies $(16-20 \mathrm{kHz})$ than at lower frequencies $(2-6 \mathrm{kHz})$. For this reason, the GS at the higher frequencies were delivered at slightly lower sound pressure levels than those at the lower frequencies (Figure 2B). Once the proper sound pressure levels were established for each mouse for all tone frequencies, including the $10 \mathrm{kHz} \mathrm{CS}$, these values were not changed anymore during the subsequent acquisition training sessions (day 1-10) and generalization test sessions (day 11-17).

\section{Eyeblink conditioning - Acquisition sessions (day 1-10)}


Eyeblink acquisition training started the day after the last baseline session. Mice were trained for ten consecutive days. Inspection of averaged traces showed that the size of eyelid responses to the CS gradually increased over the course of ten days acquisition training (Figure 4A). We quantified the CR percentage and found that three mice did not show a significant increase (Figure 4B, gray dashed lines). These three mice were therefore disregarded in any further analysis, since our main question focuses on stimulus generalization in animals that had learned the task properly. In the remaining 11 animals, we found a statistically significant main effect of session for the average CR percentage (Figure 4B; Table 1; $\mathrm{F}(9,90)=10.85, \mathrm{p}<.0001$, ANOVA on LME). Mice reached a stable CR percentage of about 65-70 around day 8 that did not further increase. We did not find an effect of sex on CR probability, male and female mice showed identical learning curves (Figure 9A; $\mathrm{F}(9,1)=0.07, \mathrm{p}=0.79$, ANOVA on LME). Further quantification of the eyelid response amplitudes, revealed that there was a statistically significant main effect of session for CR amplitude calculated over all trials (Figure 4C; Table 1; $\mathrm{F}(9,2000)=16.56$, p <.0001, ANOVA on LME). Similar to CR percentage, there was no further increase after day 8. Based on the distribution of all eyelid responses (in Figure 4D session 8 to 10 pooled), we set an arbitrary cut-off at a FEC of 0.05 to distinguish between CRs $(>=0.05)$ and non-CRs $(<0.05)$. We calculated the CR amplitude over the $C R$ only trials and found a similar main effect of session (Figure 4E; Table 1; F(9,931)=8.14, $\mathrm{p}<.0001$, ANOVA on LME). (Also, see the distribution of FEC calculated over CR only trials from sessions 8 to 10 pooled in Figure 4F).

Finally, we looked in more detail at the adaptive timing of eyeblink CRs. As expected, the latency to CR peak showed a clear distribution centered around the onset of the expected US at $250 \mathrm{~ms}$ after CS onset (Figure 4G, H) that remained stable over ten acquisition sessions. We found no statistically significant effect of session for latency to CR peak (Figure 4G; Table 1, F $(9,931)=0.62, \mathrm{p}=0.77$, ANOVA on LME). For the latency to CR onset, we could only use 272 out of 1018 CR trials, because of alpha startle response that obscured the CR onset (Figure 3D). Similar to latency to CR peak, we could not find an effect of session for latency to $\mathrm{CR}$ onset (Figure 4I, J; Table 1, $\mathrm{F}(9,90)=1.47, \mathrm{p}=0.17$; ANOVA on LME). Overall, we concluded that the majority of animals showed normal eyeblink conditioning in terms of CR percentage, CR amplitude, and CR timing.

\section{Eyeblink conditioning - Generalization test session (day 11-17)}

After ten days of acquisition training, we tested the stimulus generalization for seven consecutive days. During these generalization test sessions mice were subjected to generalization stimuli (GS), with frequencies ranging from $2-8 \mathrm{kHz}$ and $12-20 \mathrm{kHz}$. Importantly, these GS were never reinforced with the air puff US. The GSs had the exact same duration of $280 \mathrm{~ms}$ and ramp/decay times of $25 \mathrm{~ms}$ as the $10 \mathrm{kHz} \mathrm{CS}$. Since the generalization test sessions consisted of substantially more trials wherein the tone was not reinforced with an air puff US (see methods), we carefully checked whether this would lead to any extinction of learned eyeblink CRs. We found no significant effect of session on CR percentage (Figure 5A; $\mathrm{F}(6,60)=0.60 ; \mathrm{p}=0.73$, ANOVA on LME) and thus concluded that there was no extinction of eyeblink CRs over the course of seven generalization test sessions. This allowed us to pool the data of all seven generalization test sessions to study the effect of GS tone frequency on CR percentage, CR amplitude, and CR timing using the exact same criteria that were used for analyzing the acquisition training data.

$C R$ percentage: We found a significant main effect of tone frequency on CR percentage (Figure 5B, 6A; Table 2; F(9,726)=11.99, p<.0001, ANOVA on LME) with a downward gradient for CR percentage in both directions, i.e. in the direction of frequencies higher and 
lower than the $10 \mathrm{kHz}$ CS tone, although this gradient appeared less pronounced for the higher frequencies. For the $10 \mathrm{kHz}$ tone, mice had a CR percentage of $67( \pm 5)$, whereas for 2 and 20 $\mathrm{kHz}$ we found percentages of $38( \pm 6)$ and $55( \pm 6)$, respectively (all values: mean $\pm 95 \% \mathrm{CI}$ ). Post hoc comparison revealed that GSs with frequencies of $12-16 \mathrm{kHz}$ did not result in significantly different CR percentages compared to the CS, whereas GSs with frequencies between 2-8 kHz and 18-20 were statistically significant (Figure 6A). We did not find an effect of sex on CR probability, male and female mice showed identical generalization curves (Figure 9B; $\mathrm{F}(9,1)=0.45, \mathrm{p}=0.51$, ANOVA on LME). We conclude that the CR probability decreased as the GSs were more different from the trained CS and that this effect was stronger for lower frequencies than for higher frequencies.

CR amplitude - all trials: When looking at all CS only trials, we found a significant main effect of tone frequency (Figure 5C, D; Table 2; F(9,4849)=44.34, p<.0001, ANOVA on LME), with a clear downward gradient in both directions, i.e. in the direction of frequencies higher and frequencies lower than the $10 \mathrm{kHz}$ CS tone. Compared to CR percentage, the curves for both the $\mathrm{CR}$ amplitude calculated over all trials looked more symmetric. For the 10 $\mathrm{kHz}$ tone, mice had a CR amplitude calculated over all trials of $0.51( \pm 0.04)$, whereas for 2 and $20 \mathrm{kHz}$ they had amplitudes of $0.20( \pm 0.04)$ and $0.29( \pm 0.04)$, respectively (all values: mean $\pm 95 \% \mathrm{CI})$. Post hoc comparison revealed that GSs with frequencies close to the 10 $\mathrm{kHz}$ CS $(12 \mathrm{kHz})$ did not result in significantly different CR amplitudes calculated over all trials, whereas GSs with frequencies equal or higher than $14 \mathrm{kHz}$ or equal or lower than the $8 \mathrm{kHz}$ CS were all significantly different (Figure 6B; Table 3). When comparing the cumulative distributions of $\mathrm{CR}$ amplitudes calculated over all trials we found significant effects for all GS frequencies, except for the $12 \mathrm{kHz}$ GS (Figure 5E, 7A; For p values we refer to Table 4; all Kolmogorov-Smirnov test with correction for multiple comparison using FDR).

CR amplitude - CR only trials: We found a significant main effect of tone frequency for CR amplitude calculated over only trials with a CR (Figure 5F, G; Table 2; F(9,2692)=16.70, $\mathrm{p}<.0001$, ANOVA on LME), with a downward gradient in both directions, i.e. in the direction of frequencies higher and frequencies lower than the $10 \mathrm{kHz} \mathrm{CS}$ tone. For the 10 $\mathrm{kHz}$ tone, mice had a CR amplitude calculated over CR trials of $0.63( \pm 0.04)$, whereas for 2 and $20 \mathrm{kHz}$ we found amplitudes of $0.42( \pm 0.05)$ and $0.46( \pm 0.05)$, respectively (all values mean $\pm 95 \%$ CI). Similar to CR amplitude calculated over all CS trials, we found that post hoc comparison revealed that GSs with frequencies close to the $10 \mathrm{kHz}$ CS $(12 \mathrm{kHz}) \mathrm{did}$ not result in significantly different CR amplitudes whereas GSs with frequencies equal or higher than $14 \mathrm{kHz}$ or equal or lower than the $8 \mathrm{kHz}$ CS were all significantly different (Figure 6C; Table 3). Interestingly, when comparing the cumulative distributions of $\mathrm{CR}$ amplitudes calculated over CR only trials, we found a pattern that looked slightly different from the one we found for CR amplitude calculated over all trials (Figure 5H). Although there was still a clear gradient, the range was narrower and GS frequencies of 6,12 and $14 \mathrm{kHz}$ did not result in statistically significant CR amplitudes (Figure 7B; for $\mathrm{p}$ values we refer to Table 4. All Kolmogorov-Smirnov test with correction for multiple comparisons using FDR). Previous work in rabbits showed a "binary choice phenomenon" (Khilkevich et al., 2018) whereby the probability of CRs gradually decreased on the degree of similarity between the GS and CS, but the amplitude of the CR remained constant. Since the CR threshold of 0.05 FEC is rather arbitrary, we also looked at higher CR thresholds of $0.10,0.15,0.20,0.25$, but could not establish a binary choice phenomenon (Figure 8A-D). Lastly, we established the threshold that would provide us with a binary choice, by step-wise increasing the CR threshold. We 
426 found that a CR threshold of 0.45 was needed in order to get a non-significant effect of any of 427 the tone frequencies (Figure 8E).

Latency to CR onset and peak: Finally, we studied the effect of GS frequency on the timing of eyeblink CRs. As measures for CR timing, we looked at latency to CR onset and latency to $\mathrm{CR}$ peak. We found a significant main effect of tone frequency on latency to CR peak (Figure 5I, 6D; Table 2; F(9,2692) $=5.56$, p<.0001, ANOVA on LME). Interestingly, we found a gradient whereby it appeared that the lowest frequencies resulted in CR peaks with the shortest latencies and the highest frequencies in CR peaks with the longest latencies. Post hoc comparison revealed that only the GS with the highest frequency $(20 \mathrm{kHz})$ resulted in a significantly longer latency to $\mathrm{CR}$ peak compared to those to the $10 \mathrm{kHz} \mathrm{CS}$. We thus conclude that tone frequency in mice has no effect on the latency to CR onset, but does have a mild effect on latency to CR peak. We found no significant main effect of tone frequency on latency to CR onset (Figure 5J, 6E; Table $2 \mathrm{~F}(9,322)=1.12$, $\mathrm{p}=0.34$, ANOVA on LME).

441

442 Regardless of CS or GS tone frequency, the latency to CR onset was around $150 \mathrm{~ms}$ after CS onset. 
444

445

446

447

448

449

450

451

452

453

454

455

456

457

458

459

460

461

462

463

464

465

466

467

468

469

470

471

472

473

474

475

476

477

478

479

480

481

482

483

484

485

486

487

488

489

490

491

492

493

\section{Discussion}

We found that mice show a strong generalization of conditioned responses (CRs) in Pavlovian eyeblink conditioning using a tone as conditional stimulus. Both CR probability and CR amplitude decreased as the generalization stimuli (GSs) were more different from the conditional stimulus (CS). We also found a minor effect on the adaptive timing of eyeblink CRs whereby the tone lowest frequencies resulted in CR peaks with the shortest latencies and the highest frequencies in $\mathrm{CR}$ peaks with the longest latencies. No effect was found for latency to $\mathrm{CR}$ onset. Hence, our study provides a first investigation of stimulus generalization for eyeblink conditioning in mice using generalization stimuli (GSs) with tone frequencies higher and lower than the conditional stimulus (CS).

The cerebellum embodies more than two-thirds of all neurons in our brain and takes part to a large extent in the formation of procedural memories in motor behavior (De Zeeuw $\&$ Ten Brinke, 2015). Converging evidence highlights the role for cerebellum also in nonmotor functions, such as social cognition (Van Overwalle et al., 2015), emotional processing (Schmahmann \& Caplan, 2006), social behavior (Schmahmann \& Sherman, 1998), addiction (Miquel et al., 2009; Moulton et al., 2014; Volkow et al., 2003), and fear learning (Lange et al., 2015; Maschke et al., 2003). Based on our finding that mice show a strong stimulus generalization in eyeblink conditioning, we expect that cerebellum is capable to regulate stimulus generalization both in motor and non-motor domains.

\section{Differential versus non-differential training}

Eyeblink conditioning can be performed according to a non-differential or differential protocol. During non-differential training, which is the paradigm we employed in our current study, subjects are trained with only one CS, for instance a $10 \mathrm{kHz}$ tone, and tested with GSs after acquisition training is finished. During differential training, instead, subjects are trained with more than one CS, whereby one CS (CS+) is reinforced with a US and one or several other CSs are not reinforced at all (CS-). Since previous work has shown that these different eyeblink conditioning protocols have an effect on the stimulus generalization gradient (Hupka et al., 1969; Moore \& Mis, 1973), we will mainly compare our findings with previous studies using a non-differential protocol.

\section{CR percentage}

CR probability decreases with each incremental or decremental $2 \mathrm{kHz}$ step away from the trained $10 \mathrm{kHz}$ CS. Still, mice show CRs in a respectable amount of the trials at the upper and lower limits that we tested in this study: where the $10 \mathrm{kHz}$ CS evoked CRs in about $67 \%$ percent of the trials, the lower limit $2 \mathrm{kHz}$ and upper limit $20 \mathrm{kHz}$ probe CS evoked CRs in $38 \%$ and $55 \%$ of the trials, respectively. This gradient in CR probability was seen both at a mouse individual level as well as a group level (Figure 5B), indicating that the gradient was not simply a smoothing effect due to averaging data (Razran, 1949). Previous studies on stimulus generalization during non-differential eyeblink conditioning primarily looked at CR percentage (i.e., CR probability) (Table 5). Rabbits generally show a CR probability pattern that looks very similar to the one we observed in mice: the highest CR probability to the trained CS and progressive decrease in response probability to more distant GS frequencies (Garcia et al., 2003; Khilkevich et al., 2018; Moore, 1964; Moore \& Mis, 1973; Siegel et al., 1968; Solomon \& Moore, 1975). None of these studies, though, assessed GSs in both directions of the frequency spectrum, i.e., for tone frequencies higher and lower than the CS

(Table 5). Interestingly, rabbits trained using a differential eyeblink conditioning protocol yielded a steeper CR gradient in stimulus generalization testing than those trained in a nondifferential procedure (Liu, 1971; Moore, 1964). 


\section{CR amplitude}

Similar to CR percentage, the amplitude of conditioned eyelid closure calculated across all CS trials shows a stepwise decrease when the difference between the trained CS and GS increases. Since CR probability and amplitude of eyelid closure show a strong covariation on a single session level, this is not a surprising result. Indeed, previous studies done in rabbits, show the same phenomenon for eyelid closure calculated over all trials. For instance, Garcia et al. (2003) and Ohyama et al. (2003) report that the magnitude (i.e., CR amplitude calculated over all CS trials) of eyeblink responses shows a progressive decrease with each incremental step in tone frequency away from the CS. In addition, Khilkevich et al. (2018), using electrical stimulation of mossy fibers as CS, similarly show that GSs with stimulation frequencies lower than the CS result in a lower CR amplitude.

Only a subset of previous studies also describes the amplitude of eyelid closure for only those trials wherein the animal shows a CR (Garcia et al., 2003; Kehoe et al., 1995; Khilkevich et al., 2018). Looking at this value in our study, using a $0.05 \mathrm{CR}$ criterion, we again observed the same gradient with the highest CR amplitude to the trained CS and a progressive decrease in CR amplitude for each incremental or decremental $2 \mathrm{kHz}$ step away from the CS. Although this gradient was less steep than for CR amplitude calculated over all trials, we could not establish the clear binary choice phenomenon reported by Khilkevich et al., 2018, whereby the probability of CRs gradually decreased on the degree of similarity between the GS and CS, but the amplitude of the CR remained constant. Since a FEC of 0.05 is an arbitrary CR threshold, we also looked at higher CR thresholds (Figure 8B-E), but could not establish the binary choice. The most parsimonious explanation for this discrepancy between our study and Khilkevich et al., 2018, is the difference in the eyelid motor plant between mice and rabbits. In mice, the main force driving eyeblink CRs comes from contraction of the orbicularis oculi muscle, while in rabbits (and humans) there is, in addition to the contraction of the orbicularis oculi muscle, a more pronounced role for a simultaneous relaxation of the levator palpebrae muscle (Ansari \& Nadeem, 2016). This results in a different CR expression profiles, whereby conditioned rabbits show a clear bimodal (or better: zero-inflated) distribution of CR amplitudes (Garcia et al., 2003; Khilkevich et al., 2018). For mice, this bimodal distribution is present, but clearly less obvious compared to the ones reported for rabbits (Albergaria et al., 2018; Kloth et al., 2015; ten Brinke et al., 2017) (Compare histograms in Figure 4D, $\mathbf{F}$ with those reported in Khilkevich et al., 2018 Figure 2A).

Another difference between our study and the Khilkevich et al., 2018 study, is the performance level of the animals at the end of training. Khilkevich et al. trained their rabbits "until both CR percentage was high $(\mathrm{CR} \%>90 \%)$ and $\mathrm{CR}$ amplitudes were robust and near the target amplitude" In practice, this meant that most rabbits were trained for ten sessions. In our experiment, mice reached maximum conditioning levels of about $70 \% \mathrm{CRs}$ and CR amplitudes of about 0.5. These values for our mice did not further increase and remained stable after acquisition session 8. Thus, the Khilkevich (2018) rabbits were clearly performing better than our mice: the rabbits were overtrained, whereas in our mice there was theoretically still room for further improvement. This difference in performance level could also explain why Khilkevich et al., 2018 report a binary choice and we observe more a continuum of responses.

\section{CR timing}

Most previous studies on stimulus generalization during eyeblink conditioning ignored the adaptive timing properties of eyelid CRs (Khilkevich et al., 2018; Liu, 1971; Moore, 1964; Moore \& Mis, 1973; Siegel et al., 1968). Our data show that mice CRs peaked significantly 
544 later to GSs with higher frequencies compared to those with lower frequencies. These 545 findings are in line with response patterns described by Garcia and colleagues (2003). 546 Interestingly, when electrical stimulation of the forelimb, that had served as a CS, was 547 suddenly switched from $50 \mathrm{kHz}$ to a $100 \mathrm{kHz}$ stimulus train, an opposite effect was reported: 548 the latency to CR peak was shorter for the higher frequency stimulus (Svensson et al., 1997).

549 We have no clear explanation for this effect of tone frequency on latency to CR peak. It may 550 reflect processing of auditory information between the level of sensory organs (cochlea) and 551 the cerebellar mossy fiber input system.

552

553

554

555

556

557

558

559

560

561

562

563

564

565

566

567

568

569

570

571

572

573

574

575

576

577

578

579

580

581

582

583

584

585

586

587

588

589

590

In mice, there is no effect of tone frequency on the latency to CR onset. This finding is in line with previous work in mice, showing that the latency to CR onset is rather unaffected by the duration of the CS (Chettih et al., 2011), which is another difference between eyeblink CRs in mice compared to other species (rabbits, humans, ferrets). Indeed, a trending (but not significant) increase in CR onset latency has been described for stimulus generalization in rabbits (Garcia et al., 2003).

\section{Latent inhibition}

Three out of fourteen animals did not learn the task within the ten days of acquisition training, which is slightly higher compared to previous work by our group (Beekhof et al., 2021; Boele et al., 2018; de Oude et al., 2021; Grasselli et al., 2020). The difference between this study and previous work, is the amount of CS pre-exposure during the ten baseline sessions, which potentially leads to 'latent inhibition'. Latent inhibition is the phenomenon whereby it takes longer to get conditioned to a familiar stimulus than to novel stimulus. The pre-exposure to the CS (20 in total) and GS (20 in total for each frequency) during the ten baseline sessions could explain why these 3 animals did not learn the task. Although we made sure all animals received the exact same amount of CS-only and GS-only trials during the baseline sessions to keep the novelty level of the tone equal for all animals, it could be that the latent inhibition effect varies between animals.

\section{Comparison between generalization curves from eyeblink conditioning and fear conditioning}

Stimulus generalization has been studied previously using fear conditioning. However, to our knowledge, a complete assessment of conditioned fear responses as a function of a wide range of tone frequency is missing: all studies probed generalization of fear responses presenting only one or a few novel auditory cue(s) (see for instance: Shaban et al., 2006; Zhang et al., 2019). In addition, most fear conditioning studies use a differential paradigm during acquisition. For these two reasons combined, it is almost impossible to compare our eyeblink conditioning generalization curve with those using fear conditioning. It would be interesting to find out how US intensity affects the shape of the generalization curve. One could do so using eyeblink conditioning, using a stronger US, which is known to induce more fear (Boele et al., 2010) and leads to faster acquisition (Freeman et al., 1993; Kehoe \& White, 2002; Passey, 1948; Smith, 1968; Spence et al., 1953 - see Boele et al., 2016). Based on work done on fear conditioning (Dunsmoor et al., 2009, 2017; Laxmi et al., 2003), we predict that a more aversive US leads to stronger generalization (i.e., a less steep gradient). In addition, the training paradigm (differential vs. non-differential training) has effects on the shape of the curve (Dunsmoor \& LaBar, 2013).

\section{Neural mechanisms}

The study of stimulus generalization primarily comes from fields of ethology or experimental

592

593 psychology and has been investigated with various experimental paradigms other than Pavlovian eyeblink conditioning, such as fear conditioning and operant conditioning. These 
594

595

596

597

598

599

600

601

602

603

604

605

606

607

608

609

610

611

612

613

614

615

616

617

618

619

620

621

622

623

624

625

626

627

628

629

630

631

632

633 investigations on stimulus generalization have been performed in many species including humans, goldfishes, rats and pigeons, and generally report a decreasing generalization gradient when moving away from the trained stimulus (Baron, 1973; Ghirlanda \& Enquist, 2003; Thomas \& Mitchell, 1962), similar to what we found in Pavlovian eyeblink conditioning in mice. Interestingly, Guttman and Kalish (1956) showed that stimulus generalization does not originate from a failure in perceptual discrimination, but instead it is an active process. This principle probably also applies to cerebellar learning rules during eyeblink conditioning. Although early reports on stimulus generalization in eyeblink conditioning have shown that lesions of non-cerebellar structures, for instance hippocampus or cerebral cortex, affect eyeblink conditioning and stimulus generalization in eyeblink conditioning (Solomon \& Moore, 1975), the leading idea now is that the essential eyeblink conditioning memory trace is formed in cerebellum (Freeman, 2015; Freeman \& Steinmetz, 2011; Heiney et al., 2014; Mauk \& Buonomano, 2004; Mauk \& Donegan, 1997; Mccormick et al., 1981, 1981; McCormick et al., 1982; ten Brinke et al., 2015; Yeo \& Hesslow, 1998). Purkinje cells in well-defined microzones in cerebellar cortex receive converging inputs from the mossy fiber - parallel fiber pathway, which transmits the CS, and the climbing fiber pathway, which transmits the US (De Zeeuw et al., 2021; De Zeeuw \& Ten Brinke, 2015). Repeated pairing of CS and US leads to the acquisition of a simple spike pause in Purkinje cells in response to the CS (Jirenhed et al., 2017; Narain et al., 2018; Ohmae \& Medina, 2015; ten Brinke et al., 2015). Although further research is needed, one could imagine that the higher and lower frequency tones are not equally represented in the parallel fiber beams and thereby contributing to the asymmetric distribution in the stimulus - response relation.

The simple spike pause in turn causes a temporary disinhibition of cerebellar nuclei neurons, which (indirectly) innervate the motor neurons that control the eyelid musculature (Halverson et al., 2015, 2018; Jirenhed et al., 2017; ten Brinke et al., 2017). In addition, mossy fiber and climbing fibers send of collaterals directly to the cerebellar nuclei. Our previous work has shown that the number of varicosities on these mossy fiber collaterals in the cerebellar nuclei increases quite robustly with eyeblink conditioning (Boele et al., 2013). Moreover, the number of these varicosities correlates positively with the amplitude of eyelid CRs, indicating that these mossy fibers are important for CR expression. Work by Ohyama and colleagues (2003) has shown that pharmaceutical disconnection of Purkinje cell inhibition from the cerebellar nuclei results in much smaller CRs to GSs, but that CRs to the trained CS remained largely the same in size, although the adaptive timing of these CRs was affected (Ohyama, 2003). This suggests that mossy fiber collaterals form a CS-specific pathway from the pontine nuclei to the cerebellar nuclei. We hypothesize that cerebellar cortex and nuclei play synergistic roles in CR expression and timing. GSs that resemble the $\mathrm{CS}$ will result in a rather similar and strong neural representation in the parallel fiber input at the Purkinje cell, resulting in a rather similar simple spike pause. GSs that are more different instead, will result in a weaker representation, leading to a weaker Purkinje cell response. 
634

635

636

637

638

639

640

641

642

643

644

645

646

647

648

649

650

651

652

653

654

655

656

657

658

659

660

661

662

663

664

665

666

667

668

669

670

671

672

673

674

675

676

677

678

679

680

681

\section{References:}

Aarts, E., Verhage, M., Veenvliet, J. V., Dolan, C. V., \& van der Sluis, S. (2014). A solution to dependency: Using multilevel analysis to accommodate nested data. Nature Neuroscience, 17(4), 491-496. https://doi.org/10.1038/nn.3648

Akil, O., Oursler, A., Fan, K., \& Lustig, L. (2016). Mouse Auditory Brainstem Response Testing. BIO-PROTOCOL, 6(6). https://doi.org/10.21769/BioProtoc.1768

Alba, A. (1994). Deficient cerebellar long-term depression and impaired motor learning in mGluR1 mutant mice. Cell, 79(2), 377-388. https://doi.org/10.1016/00928674(94)90205-4

Albergaria, C., Silva, N. T., Pritchett, D. L., \& Carey, M. R. (2018). Locomotor activity modulates associative learning in mouse cerebellum. Nature Neuroscience, 21(5), 725-735. https://doi.org/10.1038/s41593-018-0129-x

Ansari, M. W., \& Nadeem, A. (2016). Anatomy of the Eyelids. In M. W. Ansari \& A. Nadeem, Atlas of Ocular Anatomy (pp. 53-63). Springer International Publishing. https://doi.org/10.1007/978-3-319-42781-2_5

Bang, S. J., Allen, T. A., Jones, L. K., Boguszewski, P., \& Brown, T. H. (2008). Asymmetrical stimulus generalization following differential fear conditioning. Neurobiology of Learning and Memory, 90(1), 200-216. https://doi.org/10.1016/j.nlm.2008.02.009

Baron, A. (1973). Postdiscrimination gradients of human subjects on a tone continuum. Journal of Experimental Psychology, 101(2), 337-342. https://doi.org/10.1037/h0035206

Beekhof, G. C., Osório, C., White, J. J., van Zoomeren, S., van der Stok, H., Xiong, B., Nettersheim, I. H., Mak, W. A., Runge, M., Fiocchi, F. R., Boele, H.J., Hoebeek, F. E., \& Schonewille, M. (2021). Differential spatiotemporal development of Purkinje cell populations and cerebellum-dependent sensorimotor behaviors. ELife, 10, e63668. https://doi.org/10.7554/eLife.63668

Boele, H.J. (2010). Cerebellar and extracerebellar involvement in mouse eyeblink conditioning: The ACDC model. Frontiers in Cellular Neuroscience, 3. https://doi.org/10.3389/neuro.03.019.2009

Boele, H.J., Peter, S., Ten Brinke, M. M., Verdonschot, L., IJpelaar, A. C. H., Rizopoulos, D., Gao, Z., Koekkoek, S. K. E., \& De Zeeuw, C. I. (2018). Impact of parallel fiber to Purkinje cell long-term depression is unmasked in absence of inhibitory input. Science Advances, 4(10), eaas9426. https://doi.org/10.1126/sciadv.aas9426

Boele, H.J., ten Brinke, M. M., \& De Zeeuw, C. I. (2016). Classical Conditioning of Timed Motor Responses. In The Neuronal Codes of the Cerebellum (pp. 53-96). Elsevier. https://doi.org/10.1016/B978-0-12-801386-1.00003-4

Boele, H.J., Koekkoek, S. K. E., De Zeeuw, C. I., \& Ruigrok, T. J. H. (2013). Axonal Sprouting and Formation of Terminals in the Adult Cerebellum during Associative Motor Learning. Journal of Neuroscience, 33(45), 17897-17907. https://doi.org/10.1523/JNEUROSCI.0511-13.2013

Boyden, E. S. (2015). Optogenetics and the future of neuroscience. Nature Neuroscience, 18(9), 1200-1201. https://doi.org/10.1038/nn.4094

Chettih, S. N., McDougle, S. D., Ruffolo, L. I., \& Medina, J. F. (2011). Adaptive Timing of Motor Output in the Mouse: The Role of Movement Oscillations in Eyelid Conditioning. Frontiers in Integrative Neuroscience, 5. https://doi.org/10.3389/fnint.2011.00072 
682

683

684

685

686

687

688

689

690

691

692

693

694

695

696

697

698

699

700

701

702

703

704

705

706

707

708

709

710

711

712

713

714

715

716

717

718

719

720

721

722

723

724

725

726

727

728

729

730

731

de Oude, N. L., Hoebeek, F. E., ten Brinke, M. M., de Zeeuw, C. I., \& Boele, H.J. (2021). Pavlovian eyeblink conditioning is severely impaired in tottering mice. Journal of Neurophysiology, 125(2), 398-407. https://doi.org/10.1152/jn.00578.2020

De Zeeuw, C. I., Lisberger, S. G., \& Raymond, J. L. (2021). Diversity and dynamism in the cerebellum. Nature Neuroscience, 24(2), 160-167. https://doi.org/10.1038/s41593020-00754-9

De Zeeuw, C. I., \& Ten Brinke, M. M. (2015). Motor Learning and the Cerebellum. Cold Spring Harbor Perspectives in Biology, 7(9), a021683. https://doi.org/10.1101/cshperspect.a021683

Deisseroth, K. (2011). Optogenetics. Nature Methods, 8(1), 26-29. https://doi.org/10.1038/nmeth.f.324

Dent, M. L., Fay, R. R., \& Popper, A. N. (Eds.). (2018). Rodent Bioacoustics (Vol. 67). Springer International Publishing. https://doi.org/10.1007/978-3-319-92495-3

Dunsmoor, J. E., Kroes, M. C. W., Braren, S. H., \& Phelps, E. A. (2017). Threat intensity widens fear generalization gradients. Behavioral Neuroscience, 131(2), 168-175. https://doi.org/10.1037/bne0000186

Dunsmoor, J. E., \& LaBar, K. S. (2013). Effects of discrimination training on fear generalization gradients and perceptual classification in humans. Behavioral Neuroscience, 127(3), 350-356. https://doi.org/10.1037/a0031933

Dunsmoor, J. E., Mitroff, S. R., \& LaBar, K. S. (2009). Generalization of conditioned fear along a dimension of increasing fear intensity. Learning \& Memory, 16(7), 460-469. https://doi.org/10.1101/lm.1431609

Dymond, S., Dunsmoor, J. E., Vervliet, B., Roche, B., \& Hermans, D. (2015). Fear Generalization in Humans: Systematic Review and Implications for Anxiety Disorder Research. Behavior Therapy, 46(5), 561-582. https://doi.org/10.1016/j.beth.2014.10.001

Freeman, J. H. (2015). Cerebellar learning mechanisms. Brain Research, 1621, 260-269. https://doi.org/10.1016/j.brainres.2014.09.062

Freeman, J. H., Spencer, C. O., \& Skelton, R. W. (1993). Ontogeny of eyeblink conditioning in the rat: Effects of US intensity and interstimulus interval on delay conditioning. 10.

Freeman, J. H., \& Steinmetz, A. B. (2011). Neural circuitry and plasticity mechanisms underlying delay eyeblink conditioning. Learning \& Memory, 18(10), 666-677. https://doi.org/10.1101/lm.2023011

Gao, Z., Proietti-Onori, M., Lin, Z., ten Brinke, M. M., Boele, H.J., Potters, J.-W., Ruigrok, T. J. H., Hoebeek, F. E., \& De Zeeuw, C. I. (2016). Excitatory Cerebellar Nucleocortical Circuit Provides Internal Amplification during Associative Conditioning. Neuron, 89(3), 645-657. https://doi.org/10.1016/j.neuron.2016.01.008

Garcia, K. S., Mauk, M. D., Weidemann, G., \& Kehoe, E. J. (2003). Covariation of alternative measures of responding in rabbit (Oryctolagus cuniculus) eyeblink conditioning during acquisition training and tone generalization. Behavioral Neuroscience, 117(2), 292-303. https://doi.org/10.1037/0735-7044.117.2.292

Ghirlanda, S., \& Enquist, M. (2003). A century of generalization. Animal Behaviour, 66(1), 15-36. https://doi.org/10.1006/anbe.2003.2174

Grasselli, G., Boele, H.J., Titley, H. K., Bradford, N., van Beers, L., Jay, L., Beekhof, G. C., Busch, S. E., De Zeeuw, C. I., Schonewille, M., \& Hansel, C. (2020). SK2 channels in cerebellar Purkinje cells contribute to excitability modulation in motor-learningspecific memory traces. PLOS Biology, 18(1), e3000596. https://doi.org/10.1371/journal.pbio.3000596

Halverson, H. E., Khilkevich, A., \& Mauk, M. D. (2015). Relating Cerebellar Purkinje Cell Activity to the Timing and Amplitude of Conditioned Eyelid Responses. Journal of 
Neuroscience, 35(20), 7813-7832. https://doi.org/10.1523/JNEUROSCI.366314.2015

Halverson, H. E., Khilkevich, A., \& Mauk, M. D. (2018). Cerebellar Processing Common to Delay and Trace Eyelid Conditioning. The Journal of Neuroscience, 38(33), 72217236. https://doi.org/10.1523/JNEUROSCI.0430-18.2018

Heffner, H. E., \& Heffner, R. S. (2007). Hearing Ranges of Laboratory Animals. Journal of the American Association for Laboratory Animal Science, 3.

Heiney, S. A., Wohl, M. P., Chettih, S. N., Ruffolo, L. I., \& Medina, J. F. (2014). CerebellarDependent Expression of Motor Learning during Eyeblink Conditioning in HeadFixed Mice. The Journal of Neuroscience, 34(45), 14845-14853. https://doi.org/10.1523/JNEUROSCI.2820-14.2014

Hovland, C. I. (1937). The Generalization of Conditioned Responses: I. The Sensory Generalization of Conditioned Responses with Varying Frequencies of Tone. The Journal of General Psychology, 17(1), 125-148. https://doi.org/10.1080/00221309.1937.9917977

Huang, J.-M., Money, M. K., Berlin, C. I., \& Keats, B. J. B. (1995). Auditory phenotyping of heterozygous sound-responsive $(+/ \mathrm{dn})$ and deafness $(\mathrm{dn} / \mathrm{dn})$ mice. Hearing Research, 88(1-2), 61-64. https://doi.org/10.1016/0378-5955(95)00099-P

Hupka, R. B., Liu, S. S., \& Moore, J. W. (1969). Auditory differential conditioning of the rabbit nictitating membrane response: V. Stimulus generalization as a function of the position of CS+ and CS on the frequency dimension. Psychonomic Science, 15(3), 129-131. https://doi.org/10.3758/BF03336238

Ingham, N. J., Pearson, S., \& Steel, K. P. (2011). Using the Auditory Brainstem Response (ABR) to Determine Sensitivity of Hearing in Mutant Mice. Current Protocols in Mouse Biology, 1(2), 279-287. https://doi.org/10.1002/9780470942390.mo110059

Ison, J. R., Allen, P. D., \& O’Neill, W. E. (2007). Age-Related Hearing Loss in C57BL/6J Mice has both Frequency-Specific and Non-Frequency-Specific Components that Produce a Hyperacusis-Like Exaggeration of the Acoustic Startle Reflex. JARO: Journal of the Association for Research in Otolaryngology, 8(4), 539-550. https://doi.org/10.1007/s10162-007-0098-3

Jirenhed, D.-A., Rasmussen, A., Johansson, F., \& Hesslow, G. (2017). Learned response sequences in cerebellar Purkinje cells. Proceedings of the National Academy of Sciences, 114(23), 6127-6132. https://doi.org/10.1073/pnas.1621132114

Kehoe, E. J., Horne, A. J., \& Macrae, M. (1995). Learning to Learn: Real-Time Features and a Connectionist Model. Adaptive Behavior, 3(3), 235-271. https://doi.org/10.1177/105971239500300301

Kehoe, E. J., \& white, N. E. (2002). Extinction revisited: Similarities between extinction and reductions in US intensity in classical conditioning of the rabbit's nictitating membrane response. Animal Learning \& Behavior, 30(2), 96-111. https://doi.org/10.3758/BF03192912

Khilkevich, A., Canton-Josh, J., DeLord, E., \& Mauk, M. D. (2018). A cerebellar adaptation to uncertain inputs. Science Advances, 4(5), eaap9660. https://doi.org/10.1126/sciadv.aap9660

King, J., Insanally, M., Jin, M., Martins, A. R. O., D’amour, J. A., \& Froemke, R. C. (2015). Rodent auditory perception: Critical band limitations and plasticity. Neuroscience, 296, 55-65. https://doi.org/10.1016/j.neuroscience.2015.03.053

Kloth, A. D., Badura, A., Li, A., Cherskov, A., Connolly, S. G., Giovannucci, A., Bangash, M. A., Grasselli, G., Peñagarikano, O., Piochon, C., Tsai, P. T., Geschwind, D. H., Hansel, C., Sahin, M., Takumi, T., Worley, P. F., \& Wang, S. S.-H. (2015). Cerebellar 
associative sensory learning defects in five mouse autism models. ELife, 4, e06085. https://doi.org/10.7554/eLife.06085

Koekkoek, S. K. E., Den Ouden, W. L., Perry, G., Highstein, S. M., \& De Zeeuw, C. I. (2002). Monitoring Kinetic and Frequency-Domain Properties of Eyelid Responses in Mice With Magnetic Distance Measurement Technique. Journal of Neurophysiology, 88(4), 2124-2133. https://doi.org/10.1152/jn.2002.88.4.2124

Lange, I., Kasanova, Z., Goossens, L., Leibold, N., De Zeeuw, C. I., van Amelsvoort, T., \& Schruers, K. (2015). The anatomy of fear learning in the cerebellum: A systematic meta-analysis. Neuroscience \& Biobehavioral Reviews, 59, 83-91. https://doi.org/10.1016/j.neubiorev.2015.09.019

Lashley, K. S., \& Wade, M. (1946). The Pavlovian theory of generalization. Psychological Review, 53(2), 72-87. https://doi.org/10.1037/h0059999

Laxmi, T. R., Stork, O., \& Pape, H.-C. (2003). Generalisation of conditioned fear and its behavioural expression in mice. Behavioural Brain Research, 145(1-2), 89-98. https://doi.org/10.1016/S0166-4328(03)00101-3

Lissek, S., Biggs, A. L., Rabin, S. J., Cornwell, B. R., Alvarez, R. P., Pine, D. S., \& Grillon, C. (2008). Generalization of conditioned fear-potentiated startle in humans: Experimental validation and clinical relevance. Behaviour Research and Therapy, 46(5), 678-687. https://doi.org/10.1016/j.brat.2008.02.005

Liu, S. S. (1971). Differential conditioning and stimulus generalization of the rabbit's nictitating membrane response. Journal of Comparative and Physiological Psychology, 77(1), 136-142. https://doi.org/10.1037/h0031587

Lubow, R. (1973). Latent inhibition. Psychological Bulletin, 79(6), 398-407. https://doi.org/10.1037/h0034425

Lubow, R., \& Moore, A. (1959). Latent inhibition: The effect of nonreinforced pre-exposure to the conditional stimulus. Journal of Comparative and Physiological Psychology, 52, 415-419. https://doi.org/10.1037/h0046700

Maschke, M., Erichsen, M., Drepper, J., Jentzen, W., Müller, S. P., Kolb, F. P., Diener, H.C., \& Timmann, D. (2003). Cerebellar representation of the eyeblink response as revealed by PET. NeuroReport, 14(10), 1371-1374. https://doi.org/10.1097/01.wnr.0000078540.07662.d9

Mauk, M. D., \& Buonomano, D. V. (2004). THE NEURAL BASIS OF TEMPORAL PROCESSING. Annual Review of Neuroscience, 27(1), 307-340. https://doi.org/10.1146/annurev.neuro.27.070203.144247

Mauk, M. D., \& Donegan, N. H. (1997). A model of Pavlovian eyelid conditioning based on the synaptic organization of the cerebellum. Learning \& Memory, 4(1), 130-158. https://doi.org/10.1101/1m.4.1.130

Mccormick, D. A., Lavond, D. G., Clark, G. A., Kettner, R. E., Rising, C. E., \& Thompson, R. F. (1981). The engram found? Role of the cerebellum in classical conditioning of nictitating membrane and eyelid responses. Bulletin of the Psychonomic Society, 18(3), 103-105. https://doi.org/10.3758/BF03333573

McCormick, D. A., Lavond, D. G., \& Thompson, R. F. (1982). Concomitant classical conditioning of the rabbit nictitating membrane and eyelid responses: Correlations and implications. Physiology \& Behavior, 28(5), 769-775. https://doi.org/10.1016/0031-9384(82)90192-5

Meulders, A., \& Vlaeyen, J. W. S. (2013). The acquisition and generalization of cued and contextual pain-related fear: An experimental study using a voluntary movement paradigm: Pain, 154(2), 272-282. https://doi.org/10.1016/j.pain.2012.10.025 
Miquel, M., Toledo, R., Garcia, L., Coria-Avila, G., \& Manzo, J. (2009). Why Should We Keep the Cerebellum in Mind When Thinking About Addiction? Current Drug Abuse Reviewse, 2(1), 26-40. https://doi.org/10.2174/1874473710902010026

Moore, J. W. (1964). Differential eyelid conditioning as a function of the frequency and intensity of auditory CSs. Journal of Experimental Psychology, 68(3), 250-259. https://doi.org/10.1037/h0040807

Moore, J. W., \& Mis, F. W. (1973). Differential conditioning along two dimensions and stimulus generalization of the rabbit's nictitating membrane response. Bulletin of the Psychonomic Society, 1(2), 123-125. https://doi.org/10.3758/BF03334316

Moulton, E. A., Elman, I., Becerra, L. R., Goldstein, R. Z., \& Borsook, D. (2014). The cerebellum and addiction: Insights gained from neuroimaging research: Cerebellum and addiction. Addiction Biology, 19(3), 317-331. https://doi.org/10.1111/adb.12101

Najafi, F., \& Medina, J. F. (2020). Bidirectional short-term plasticity during single-trial learning of cerebellar-driven eyelid movements in mice. Neurobiology of Learning and Memory, 170, 107097. https://doi.org/10.1016/j.nlm.2019.107097

Narain, D., Remington, E. D., Zeeuw, C. I. D., \& Jazayeri, M. (2018). A cerebellar mechanism for learning prior distributions of time intervals. Nature Communications, 9(1), 469. https://doi.org/10.1038/s41467-017-02516-x

Navabpour, S., Kwapis, J. L., \& Jarome, T. J. (2020). A neuroscientist's guide to transgenic mice and other genetic tools. Neuroscience \& Biobehavioral Reviews, 108, 732-748. https://doi.org/10.1016/j.neubiorev.2019.12.013

Ohmae, S., \& Medina, J. F. (2015). Climbing fibers encode a temporal-difference prediction error during cerebellar learning in mice. Nature Neuroscience, 18(12), 1798-1803. https://doi.org/10.1038/nn.4167

Ohyama, T. (2003). Stimulus Generalization of Conditioned Eyelid Responses Produced Without Cerebellar Cortex: Implications for Plasticity in the Cerebellar Nuclei. Learning \& Memory, 10(5), 346-354. https://doi.org/10.1101/lm.67103

Passey, G. E. (1948). The influence of intensity of unconditioned stimulus upon acquisition of a conditioned response. Journal of Experimental Psychology, 38(4), 420-428. https://doi.org/10.1037/h0059569

Pavlov, P. I. (1927). Conditioned reflexes: An investigation of the physiological activity of the cerebral cortex. Annals of Neurosciences, 17(3), 136-141. https://doi.org/10.5214/ans.0972-7531.1017309

Razran, G. (1949). Stimulus generalization of conditioned responses. Psychological Bulletin, 46(5), 337-365. https://doi.org/10.1037/h0060507

Reynolds, R. P., Kinard, W. L., Degraff, J. J., Leverage, N., \& Norton, J. N. (2010). Noise in a Laboratory Animal Facility from the Human and Mouse Perspectives. Journal of the American Association for Laboratory Animal Science : JAALAS, 49(5), 592-597.

Schielzeth, H., Dingemanse, N. J., Nakagawa, S., Westneat, D. F., Allegue, H., Teplitsky, C., Réale, D., Dochtermann, N. A., Garamszegi, L. Z., \& Araya-Ajoy, Y. G. (2020). Robustness of linear mixed-effects models to violations of distributional assumptions. Methods in Ecology and Evolution, 11(9), 1141-1152. https://doi.org/10.1111/2041210X.13434

Schmahmann, J. D., \& Caplan, D. (2006). Cognition, emotion and the cerebellum. Brain, 129(2), 290-292. https://doi.org/10.1093/brain/awh729

Schmahmann, J. D., \& Sherman, J. C. (1998). The cerebellar cognitive affective syndrome. 19.

Shaban, H., Humeau, Y., Herry, C., Cassasus, G., Shigemoto, R., Ciocchi, S., Barbieri, S., van der Putten, H., Kaupmann, K., Bettler, B., \& Lüthi, A. (2006). Generalization of 
amygdala LTP and conditioned fear in the absence of presynaptic inhibition. Nature Neuroscience, 9(8), 1028-1035. https://doi.org/10.1038/nn1732

Siegel, S., Hearst, E., \& George, N. (1968). Generalization gradients obtained from individual subjects following classical conditioning. Journal of Experimental Psychology, 78(1), 171-174. https://doi.org/10.1037/h0026178

Smith, D. R., Gallagher, M., \& Stanton, M. E. (2007). Genetic background differences and nonassociative effects in mouse trace fear conditioning. Learning \& Memory, 14(9), 597-605. https://doi.org/10.1101/1m.614807

Smith, M. C. (1968). CS-US interval and US intensity in classical conditioning of the rabbit's nictitating membrane response. Journal of Comparative and Physiological Psychology, 66(3, Pt.1), 679-687. https://doi.org/10.1037/h0026550

Solomon, P. R., \& Moore, J. W. (1975). Latent Inhibition and Stimulus Generalization of the Classically Conditioned Nictitating Membrane Response in Rabbits (Oryctolagus cuniculus) Following Dorsal Hippocampal Ablation. 12.

Spence, K. W., Swisher, D., \& Taylor, J. (1953). LEARNING AND PERFORMANCE IN EYELID CONDITIONING AS A FUNCTION OF INTENSITY OF THE UCS. 7.

Svensson, P., Ivarsson, M., \& Hesslow, G. (1997). Effect of varying the intensity and train frequency of forelimb and cerebellar mossy fiber conditioned stimuli on the latency of conditioned eye-blink responses in decerebrate ferrets. Learning \& Memory, 4(1), 105-115. https://doi.org/10.1101/lm.4.1.105

ten Brinke, M. M., Heiney, S. A., Wang, X., Proietti-Onori, M., Boele, H.J., Bakermans, J., Medina, J. F., Gao, Z., \& De Zeeuw, C. I. (2017). Dynamic modulation of activity in cerebellar nuclei neurons during pavlovian eyeblink conditioning in mice. ELife, 6, e28132. https://doi.org/10.7554/eLife.28132

ten Brinke, M. M., Boele, H.J., Spanke, J. K., Potters, J.-W., Kornysheva, K., Wulff, P., IJpelaar, A. C. H. G., Koekkoek, S. K. E., \& De Zeeuw, C. I. (2015). Evolving Models of Pavlovian Conditioning: Cerebellar Cortical Dynamics in Awake Behaving Mice. Cell Reports, 13(9), 1977-1988. https://doi.org/10.1016/j.celrep.2015.10.057

Thomas, D. R., \& Mitchell, K. (1962). Instructions and stimulus categorizing in a measure of stimulus generalization. Journal of the Experimental Analysis of Behavior, 5(3), 375381. https://doi.org/10.1901/jeab.1962.5-375

Turner, J. G., Parrish, J. L., Hughes, L. F., Toth, L. A., \& Caspary, D. M. (2005). Hearing in Laboratory Animals: Strain Differences and Nonauditory Effects of Noise. Comparative Medicine, 55(1), 12.

van Looij, M. A. J., Liem, S.-S., van der Burg, H., van der Wees, J., De Zeeuw, C. I., \& van Zanten, B. G. A. (2004). Impact of conventional anesthesia on auditory brainstem responses in mice. Hearing Research, 193(1-2), 75-82. https://doi.org/10.1016/j.heares.2004.02.009

Van Overwalle, F., D'aes, T., \& Mariën, P. (2015). Social cognition and the cerebellum: A meta-analytic connectivity analysis. Human Brain Mapping, 36(12), 5137-5154. https://doi.org/10.1002/hbm.23002

Volkow, N. D., Wang, G.-J., Ma, Y., Fowler, J. S., Zhu, W., Maynard, L., Telang, F., Vaska, P., Ding, Y.-S., Wong, C., \& Swanson, J. M. (2003). Expectation Enhances the Regional Brain Metabolic and the Reinforcing Effects of Stimulants in Cocaine Abusers. The Journal of Neuroscience, 23(36), 11461-11468. https://doi.org/10.1523/JNEUROSCI.23-36-11461.2003

Willott, J. F. (2006). Measurement of the Auditory Brainstem Response (ABR) to Study Auditory Sensitivity in Mice. Current Protocols in Neuroscience, 34(1), 8.21B.18.21B.12. https://doi.org/10.1002/0471142301.ns0821bs34 
927

928

929

930

931

932

933

934

935

936
Yeo, C. H., \& Hesslow, G. (1998). Cerebellum and conditioned reflexes. Trends in Cognitive Sciences, 2(9), 322-330. https://doi.org/10.1016/S1364-6613(98)01219-4

Zhang, J., Zhang, K.-Y., Zhang, L.-B., Zhang, W.-W., Feng, H., Yao, Z.-X., Hu, B., \& Chen, H. (2019). A method for combining multiple-units readout of optogenetic control with natural stimulation-evoked eyeblink conditioning in freely-moving mice. Scientific Reports, 9(1), 1857. https://doi.org/10.1038/s41598-018-37885-w

Zheng, Q. Y., Johnson, K. R., \& Erway, L. C. (1999). Assessment of hearing in 80 inbred strains of mice by ABR threshold analyses. Hearing Research, 130(1-2), 94-107. 
937 Author Contributions:

938 Conceptualization: FRF, SD, HJB

939 Methodology: FRF, SD, SKEK, HJB

940 Investigation: FRF, SD

941 Analysis: FRF, HJB

942 Visualization: FRF, HJB

943 Funding acquisition: HJB, CIDZ

944 Project administration: HJB, CIDZ

945 Supervision: HJB, CIDZ, SKEK

946 Writing - original draft: FRF, HJB

947 Writing - review \& editing: CIDZ, HJB 


\section{Figure legends:}

Figure 1 | Eyeblink conditioning setup and experimental design. (A) Mice were placed in a light- and sound- isolating chamber on a foam cylindrical treadmill that allowed them to walk freely with their heads fixed at a horizontal bar. The US (in red) consisted of a weak air puff to the left eye and the CS (in green) consisted of a $10 \mathrm{kHz}$ tone. Speakers were placed on both upper front corners of the chamber. Eyelid movements were recorded using a high-speed video camera system (300 frames per second). (B) Schematics of eyelid conditioning acquisition training and generalization test protocols. For each protocol the duration and the ratio of different trial types is presented at the top of the corresponding illustration. (C) Example eyeblink traces before, during, and after eyeblink conditioning. The CS (green) and US (red) onset and duration are shown at the top of each panel. Over the course of acquisition training, mice learn to close their eyes in response to the CS, which are called conditioned responses (CRs)

Figure 2 | Mouse auditory brainstem responses (ABRs) and auditory eyelid startle responses to a range of sound frequencies and intensities. (A) ABRs were measured at 4, 8,16 and $32 \mathrm{kHz}$. Mice were most sensitive to sounds in the range of 8 and $16 \mathrm{kHz}$ showing normal auditory thresholds. Each symbol represents one mouse. For the boxplot, the thick horizontal line is showing the median, the top edge of each box indicates the 25th percentile, bottom edge the 75th percentile, whisker lines extending above and below each box indicate the range of observations. (B) The sound pressure levels that elicits minimal auditory eyelid startle response for different sound frequencies. This value was determined for each mouse carefully during ten baseline sessions and used as conditional stimulus (CS) or generalization stimulus (GS). For complete overview of all values, we refer to Tables 1 and 2.

Figure 3 | Mouse eyelid startle responses obscure CR onset (A) Example eyelid responses to a $10 \mathrm{kHz}$ tone in a naïve unconditioned mouse presented at three different sound intensities: 60, 70, and 80 decibels $(\mathrm{dB})$. In this example the $60 \mathrm{~dB}$ tone elicits just an alpha startle response, the $70 \mathrm{~dB}$ tone an alpha and beta startle response, and the 80 an alpha and beta startle and even a response that resembles a conditioned response. For this mouse, a tone with a sound pressure level of $60 \mathrm{~dB}$ would be a proper CS for training. (B) Example eyelid responses after training taken from the same animal. In the left panel, the alpha startle response obscures the $\mathrm{CR}$ onset. In the right panel, there is no startle response and consequently the latency to CR onset can be detected reliably. (C) Separation of startle and non-startle trials was achieved by taking the first derivative of the eyelid position signal. In this velocity signal, the presence of a peak immediately after CS onset was the discriminator between startle (top panels) and non-startle trials (bottom panels). Latency to CR onset was determined non-startle trials. For all other outcome measures, startle and non-startle trials were combined. Similar to Figure 3, the blue gradient indicates GSs with frequencies higher than the $10 \mathrm{kHz}$ CS and red gradient indicates GSs with frequencies lower than the $10 \mathrm{kHz}$ CS. Each line is the averaged velocity signal of the eyeblink trace for one GS or CS frequency. For all panels: The green dashed line indicates CS onset, the red dashed line indicates expected US onset. The light green and red shadings indicate CS and US duration, respectively. Eyelid is fully open at 0 and fully closed at 1 . The US is omitted in the CS-only trials. Abbreviations: CS Conditional Stimulus (tone), US Unconditional Stimulus (eye puff). (D) Eyelid responses separated by the presence of an alpha startle response. Left panel shows eyelid traces with a startle response, right panel shows traces without a startle response. 
997 Figure 4 | Mice acquire conditioned eyelid responses over the course of ten consecutive

998 training sessions (A) Averaged eyeblink traces in CS-only trials during acquisition sessions $9991,4,7$ and 10 for the 11 mice that learned the task. The green dashed line indicates CS onset, 1000 the red dashed line indicates expected US onset. The light green and red shadings indicate CS 1001 and US duration, respectively. Eyelid is fully open at 0 and fully closed at 1 . The US is 1002 omitted in the CS-only trials. (B) CR percentage as a function of acquisition training session. 1003 Each solid gray line represents a mouse that did learn the task $(n=11)$, each dotted gray line 1004 1005 1006 1007 1008 1009 1010 represents an animal that did not learn the task, i.e., did not reach a CR percentage of more than 20 after ten training days $(n=3)$. Black line with black filled dots indicates the mean of each session for the 11 animals that learn the task. (C) Eyelid closure amplitude over all trials plotted as a function of acquisition training session. The effect of session is statistically significant. For the boxplot, the thick horizontal line is showing the median, the top edge of each box indicates the 25 th percentile, bottom edge the 75 th percentile, whisker lines extending above and below each box indicate the range of observations, the plus symbols indicate outliers. The black line plot with filled black dots indicates the mean for each acquisition session. (D) Distribution of eyelid closure amplitude calculated over all trials (acquisition sessions 8-10 pooled). Center of mass is around 0. For calculating the Eye closure - CR only trials, in panels in E-J, we used a CR criterium of 0.05 indicated with the vertical dashed line. (E) Similar to $\mathrm{C}$ but now showing eyelid closure amplitude over $C R$ only trials plotted as a function of acquisition training session. The effect of session is statistically significant. (F) Similar to (D), but now showing the distribution of eyelid closure amplitude calculated over CR only trials (acquisition session 8-10 pooled). (G) Latency to CR peak plotted as a function of training session. The green dashed line indicates CS onset, the red dashed line indicates US onset. The light green and red shadings indicate CS and US duration, respectively. There is no statistically significant effect of session. (H) Distribution of latency to CR peak for all trials (acquisition sessions 1 - 10 pooled). Note the adaptive timing of eyeblink CRs, whereby the CR peaks around the expected US (US is omitted in CS only trials) (I) Similar to (G), but now showing latency to CR onset plotted as a function of training session. There is no statistically significant effect of session. (J) Similar to (H), but now showing the distribution of latency to CR onset for all sessions. For complete statistics for all panels, we refer to Table 3.

Figure 5 | Generalization of conditioned eyelid responses in mice (A) CR percentage as a function of generalization test session. Solid gray lines represent individual mice and the black line with black filled dots indicates the mean of each session. No effect was found for generalization session, indicating that there was no extinction of eyeblink CRs during the generalization test sessions. (B) CR percentage as a function of sound frequency. The $10 \mathrm{kHz}$ tone is the conditional stimulus (CS), all other tone frequencies serve as generalization stimuli (GSs) that are never reinforced with an air puff US. Solid gray lines represent individual mice, black line with black filled dots indicates the mean percentage CR for each generalization stimulus. (C) Eyelid closure amplitude over all trials plotted as a function of sound frequency. For the boxplot, the thick horizontal line is showing the median, the top edge of each box indicates the 25th percentile, bottom edge the 75th percentile, whisker lines extending above and below each box indicate the range of observations, the plus symbols indicate outliers. The black line plot with filled black dots indicates the mean for each sound frequency used. For panels $\mathrm{C}-\mathrm{H}$, the blue gradient indicates GSs with frequencies higher than the $10 \mathrm{kHz}$ CS and red gradient indicates GSs with frequencies lower than the $10 \mathrm{kHz}$ CS. (D) Averaged eyeblink traces in response to different sound frequencies. The green dashed line indicates CS onset, the red dashed line indicates expected US onset. The light green and red shadings indicate CS and US duration, respectively. Eyelid is fully open at 0 and fully 
1047 closed at 1 . The US is omitted in the CS-only trials. Note the symmetric generalization 1048 gradient. (E) Cumulative distribution function of eyelid closure calculated over all trials for 1049 the different sound frequencies. (F) Similar to (C), but now only for trials with a CR. (G) 1050 Similar to (D), but now for trials with a CR. (H) Similar to (E), but now for trials with a CR. 1051 (I) Effect of sound frequency on the latency to CR peak. Lower tones tend to elicit eyeblink 1052 CR that peak earlier than higher tones. (J) There was no effect of sound frequency on the 1053 latency to CR onset. For complete statistics, we refer to Tables 4-6.

1054

1055

1056

1057

1058

1059

1060

1061

Figure 6 | Heatmaps showing adjusted p-values of all tone-tone comparisons for CR percentage, CR amplitude, and CR timing. (A) Effect of tone frequency on CR percentage. The angular forked black box highlights the comparison between the $10 \mathrm{kHz}$ conditional stimulus (CS) and all the generalization stimuli (GSs). Note that the heatmap is on a logarithmic scale. All p-values were adjusted for multiple comparisons using false-discovery rate (FDR). Values correspond with those of Figure 3B (B) Effect of tone frequency on eyelid closure calculated over all trials. Values correspond with those of Figure 3C (C) Effect of tone frequency on eyelid closure calculated over $C R$ only trials using a 0.05 criterium. Values correspond with those of Figure 3F (D) Effect of tone frequency on latency to CR peak. Values correspond with those of Figure 3I (E) Effect of tone frequency on latency to CR onset. Values correspond with those of Figure 3J. For complete statistics, we refer to Tables 4,5 .

1067

1068

1069

1070

Figure 7 | Heatmaps showing adjusted p-values of all tone-tone comparisons for cumulative CR amplitude. (A) Effect of tone frequency on cumulative CR amplitude calculated over all trials. Color indicates p-value. The angular forked black box highlights

1071

1072 the comparison between the $10 \mathrm{kHz}$ conditional stimulus (CS) and all generalization stimuli (GSs). Note that the heatmap is on a logarithmic scale. All p-values were calculated using a

1073

1074

1075

1076

1077

1078

1079

1080 Kolmogorov-Smirnov test on the cumulative distribution function (CDF). All p-values were adjusted for multiple comparisons using false-discovery rate (FDR). Values correspond with those of Figure 3E. (B) Similar to (A) but now for the effect of tone frequency on cumulative CR amplitude calculated over $C R$ only trials using 0.05 criterium. Values correspond with those of Figure 3H. For complete statistics, we refer to Tables 6.

Figure 8 | Heatmaps showing adjusted p-values of all tone-tone comparisons for cumulative CR amplitude using different CR thresholds (A) Effect of sound frequency on cumulative CR amplitude calculated over all trials. Color indicates p-value. The angular

1081

1082

1083

1084

1085

1086

1087

1088

1089

1090 forked black box highlights the comparison between the $10 \mathrm{kHz}$ conditional stimulus (CS) and all generalization stimuli (GSs). Note that the heatmap is on a logarithmic scale. All pvalues were calculated using a Kolmogorov-Smirnov test on the cumulative distribution function (CDF). All p-values were adjusted for multiple comparisons using false-discovery rate (FDR). Similar to Figure 3, the blue gradient indicates GSs with frequencies higher than the $10 \mathrm{kHz}$ CS and red gradient indicates GSs with frequencies lower than the $10 \mathrm{kHz}$ CS. (B-D) Similar to (A) but now using a CR criteriums of 0.10, 0.15, and 0.20 fraction eyelid closure (FEC). (E) Similar to (B-D), but now using the lowest CR threshold whereby there is a non-significant effect of GS for all frequencies. In mice, this threshold appeared to be 0.45 .

1091

1092

1093

1094

1095 Thus, a threshold of 0.45 FEC was needed to get a binary response pattern, as reported in Khilkevich et al. 2018, whereby the probability of a CR gradually decreases depending on the similarity between CS and GS, but the amplitude of the CR remained constant. Note that this 0.45 is close to the split of the bimodal distributions shown in Figure 2D, F. 
1096 Figure 9 | No effect of sex on acquisition and generalization of conditioned eyeblink 1097 responses. (A) CR percentage during acquisition sessions 1 to 10. Each colored line 1098 represents an individual mouse (yellow for females, purple for males). All animals are 1099 included $(n=14)$, also the ones that did not learn the task $(n=3)$ and are therefore excluded 1100 from the main statistical analysis of this paper. Thicker lines indicate the averages 1101 respectively for males and females including all the animals. (B) Generalization test sessions 1102 pooled together. Same color coding as in A. Here again, all animals are included in the 1103 averages.

1104

1105

1106 


\section{Tables}

Table 1| Eyeblink conditioning outcome measures during acquisition training (session 110). All values represent mean $\pm 95 \%$ CI. The ANOVA on linear mixed-effect model (LME) shows the main effect of session. Abbreviations: CR, conditioned response.

\begin{tabular}{llllll} 
Session & CR percentage & CR amp-all trials & CR amp-CR only trials & Latency to CR peak & Latency to CR onset \\
\hline $\mathbf{1}$ & $14( \pm 8)$ & $0.11( \pm 0.05)$ & $0.19( \pm 0.06)$ & $329.7( \pm 51.1)$ & $130.7( \pm 276.3)$ \\
$\mathbf{2}$ & $33( \pm 12)$ & $0.23( \pm 0.10)$ & $0.30( \pm 0.12)$ & $306.7( \pm 31.6)$ & $124.9( \pm 41.5)$ \\
$\mathbf{3}$ & $37( \pm 16)$ & $0.27( \pm 0.16)$ & $0.39( \pm 0.19)$ & $314.3( \pm 28.4)$ & $116.5( \pm 31.8)$ \\
$\mathbf{4}$ & $38( \pm 13)$ & $0.30( \pm 0.19)$ & $0.44( \pm 0.21)$ & $302.6( \pm 22.7)$ & $137.8( \pm 56.7)$ \\
$\mathbf{5}$ & $42( \pm 15)$ & $0.37( \pm 0.15)$ & $0.46( \pm 0.20)$ & $303.4( \pm 28.0)$ & $139.9( \pm 44.8)$ \\
$\mathbf{6}$ & $50( \pm 15)$ & $0.40( \pm 0.15)$ & $0.53( \pm 0.17)$ & $313.8( \pm 30.9)$ & $114.0( \pm 23.7)$ \\
$\mathbf{7}$ & $56( \pm 16)$ & $0.33( \pm 0.12)$ & $0.44( \pm 0.13)$ & $313.5( \pm 28.2)$ & $145.7( \pm 61.8)$ \\
$\mathbf{8}$ & $63( \pm 17)$ & $0.48( \pm 0.15)$ & $0.56( \pm 0.14)$ & $310.0( \pm 24.2)$ & $122.1( \pm 95.8)$ \\
$\mathbf{9}$ & $67( \pm 14)$ & $0.48( \pm 0.11)$ & $0.59( \pm 0.10)$ & $312.5( \pm 24.6)$ & $119.2( \pm 37.1)$ \\
$\mathbf{1 0}$ & $67( \pm 14)$ & $0.45( \pm 0.11)$ & $0.56( \pm 0.10)$ & $313.5( \pm 29.2)$ & $151.5( \pm 19.5)$ \\
$\begin{array}{l}\text { ANOVA } \\
\text { on LME }\end{array}$ & $\mathrm{F}(9,90)=10.85$, & $\mathrm{F}(9,2000)=16.56$, & $\mathrm{F}(9,931)=8.14$, & $\mathrm{F}(9,931)=0.62$, & $\mathrm{F}(9,90)=1.47$,
\end{tabular}

Table 2| Eyeblink conditioning outcome measures during generalization test sessions (session 11-17). All values represent mean $\pm 95 \%$ CI. The ANOVA on linear mixed-effect model (LME) shows the main effect sound frequency. Post-hoc comparisons are shown in Figure 6 and table 3 and 4. Abbreviations: CR, conditioned response.

\begin{tabular}{|c|c|c|c|c|c|}
\hline Tone freq. & CR percentage & CR amp-all trials & CR amp-CR only trials & Latency to CR peak & Latency to CR onset \\
\hline $2 \mathrm{kHz}$ & $38( \pm 6)$ & $0.20( \pm 0.04)$ & $0.42( \pm 0.05)$ & $310.0( \pm 13.9)$ & $162.5( \pm 15.0)$ \\
\hline $4 \mathrm{kHz}$ & $43( \pm 7)$ & $0.28( \pm 0.06)$ & $0.49( \pm 0.07)$ & $323.9( \pm 15.7)$ & $147.8( \pm 17.9)$ \\
\hline $6 \mathrm{kHz}$ & $50( \pm 6)$ & $0.34( \pm 0.05)$ & $0.54( \pm 0.05)$ & $311.0( \pm 9.10)$ & $158.1( \pm 21.4)$ \\
\hline $8 \mathrm{kHz}$ & $58( \pm 6)$ & $0.42( \pm 0.04)$ & $0.56( \pm 0.04)$ & $315.1( \pm 9.79)$ & $148.8( \pm 23.3)$ \\
\hline $10 \mathrm{kHz}$ & $67( \pm 5)$ & $0.51( \pm 0.04)$ & $0.63( \pm 0.04)$ & $320.1( \pm 8.96)$ & $145.3( \pm 16.0)$ \\
\hline $12 \mathrm{kHz}$ & $65( \pm 5)$ & $0.46( \pm 0.04)$ & $0.60( \pm 0.04)$ & $311.5( \pm 9.72)$ & $151.3( \pm 18.9)$ \\
\hline $14 \mathrm{kHz}$ & $63( \pm 5)$ & $0.43( \pm 0.04)$ & $0.59( \pm 0.04)$ & $327.8( \pm 10.3)$ & $142.6( \pm 13.1)$ \\
\hline $16 \mathrm{kHz}$ & $61( \pm 4)$ & $0.40( \pm 0.03)$ & $0.55( \pm 0.04)$ & $324.9( \pm 11.8)$ & $155.8( \pm 13.4)$ \\
\hline $18 \mathrm{kHz}$ & $55( \pm 6)$ & $0.31( \pm 0.04)$ & $0.47( \pm 0.05)$ & $332.1( \pm 12.5)$ & $141.2( \pm 16.0)$ \\
\hline $20 \mathrm{kHz}$ & $55( \pm 6)$ & $0.29( \pm 0.04)$ & $0.46( \pm 0.05)$ & $341.3( \pm 13.6)$ & $152.8( \pm 13.3)$ \\
\hline $\begin{array}{l}\text { ANOVA } \\
\text { on LME }\end{array}$ & $\begin{array}{l}\mathrm{F}(9,726)=11.99, \\
\mathrm{p}<.0001\end{array}$ & $\begin{array}{l}\mathrm{F}(9,4849)=44.34, \\
\mathrm{p}<.0001\end{array}$ & $\begin{array}{l}\mathrm{F}(9,2692)=16.70 \\
\mathrm{p}<.0001\end{array}$ & $\begin{array}{l}\mathrm{F}(9,2692)=5.56, \\
\mathrm{p}<.0001\end{array}$ & $\begin{array}{l}\mathrm{F}(9,322)=1.12 \\
\mathrm{p}=0.34\end{array}$ \\
\hline
\end{tabular}


Table 3| Post hoc comparison between the $10 \mathrm{kHz}$ CS and all other GS frequencies for CR amplitude calculated over all trials and CR amplitude calculated over CR trials. All values represent FDR corrected post-hoc comparisons using an ANOVA on linear mixedeffect model. Abbreviations: CS, conditional stimulus; GS, generalization stimulus.

\begin{tabular}{llllllllll} 
CS 10 kHz versus GS & $\mathbf{2 ~ k H z}$ & $\mathbf{4 ~ k H z}$ & $\mathbf{6 ~ k H z}$ & $\mathbf{8 ~ k H z}$ & $\mathbf{1 2 ~ k H z}$ & $\mathbf{1 4} \mathbf{~ k H z}$ & $\mathbf{1 6 ~ k H z}$ & $\mathbf{1 8 ~ k H z}$ & $\mathbf{2 0 ~ k H z}$ \\
\hline CR amp - all trials & $\mathrm{p}<.0001$ & $\mathrm{p}<.0001$ & $\mathrm{p}<.0001$ & $\mathrm{p}<.0001$ & $\mathrm{p}=0.056$ & $\mathrm{p}<.0001$ & $\mathrm{p}<.0001$ & $\mathrm{p}<.0001$ & $\mathrm{p}<.0001$ \\
CR amp - CR only trials & $\mathrm{p}<.0001$ & $\mathrm{p}<.0001$ & $\mathrm{p}=0.0004$ & $\mathrm{p}=0.0002$ & $\mathrm{p}=0.076$ & $\mathrm{p}=0.021$ & $\mathrm{p}<.0001$ & $\mathrm{p}<.0001$ & $\mathrm{p}<.0001$
\end{tabular}

Table 4| Post hoc comparison between the $10 \mathrm{kHz}$ CS and all other GS frequencies for cumulative CR amplitude calculated over all trials and cumulative CR amplitude calculated over $\boldsymbol{C R}$ only trials. All values represent FDR corrected post-hoc comparisons using a two-sample Kolmogorov-Smirnov test on the cumulative distribution. Abbreviations: CS, conditional stimulus; GS, generalization stimulus.

\begin{tabular}{|c|c|c|c|c|c|c|c|c|c|}
\hline CS $10 \mathrm{kHz}$ versus GS & $2 \mathrm{kHz}$ & $4 \mathrm{kHz}$ & $6 \mathrm{kHz}$ & $8 \mathrm{kHz}$ & $12 \mathrm{kHz}$ & $14 \mathrm{kHz}$ & $16 \mathrm{kHz}$ & $18 \mathrm{kHz}$ & $20 \mathrm{kHz}$ \\
\hline$\overline{\mathrm{CR} \text { a }}$ & $\mathrm{p}<.0001$ & $\mathrm{p}<.0001$ & $\mathrm{p}<.0001$ & $\mathrm{p}=0.0110$ & $\mathrm{p}=1.092$ & $\mathrm{p}=0.0105$ & $\mathrm{p}<.0001$ & $\mathrm{p}<.0001$ & $\mathrm{p}<.0001$ \\
\hline CR amp - CR only trials & $\mathrm{p}<.0001$ & $\mathrm{p}=0.0032$ & $\mathrm{p}=0.0562$ & $\mathrm{p}=0.0095$ & $\mathrm{p}=0.621$ & $\mathrm{p}=0.1067$ & $\mathrm{p}<.0001$ & $\mathrm{p}<.0001$ & $\mathrm{p}<.0001$ \\
\hline
\end{tabular}

Table 5| Overview of previous studies on stimulus generalization and Pavlovian eyeblink conditioning studies. Note that none of these studies was done in mice. 


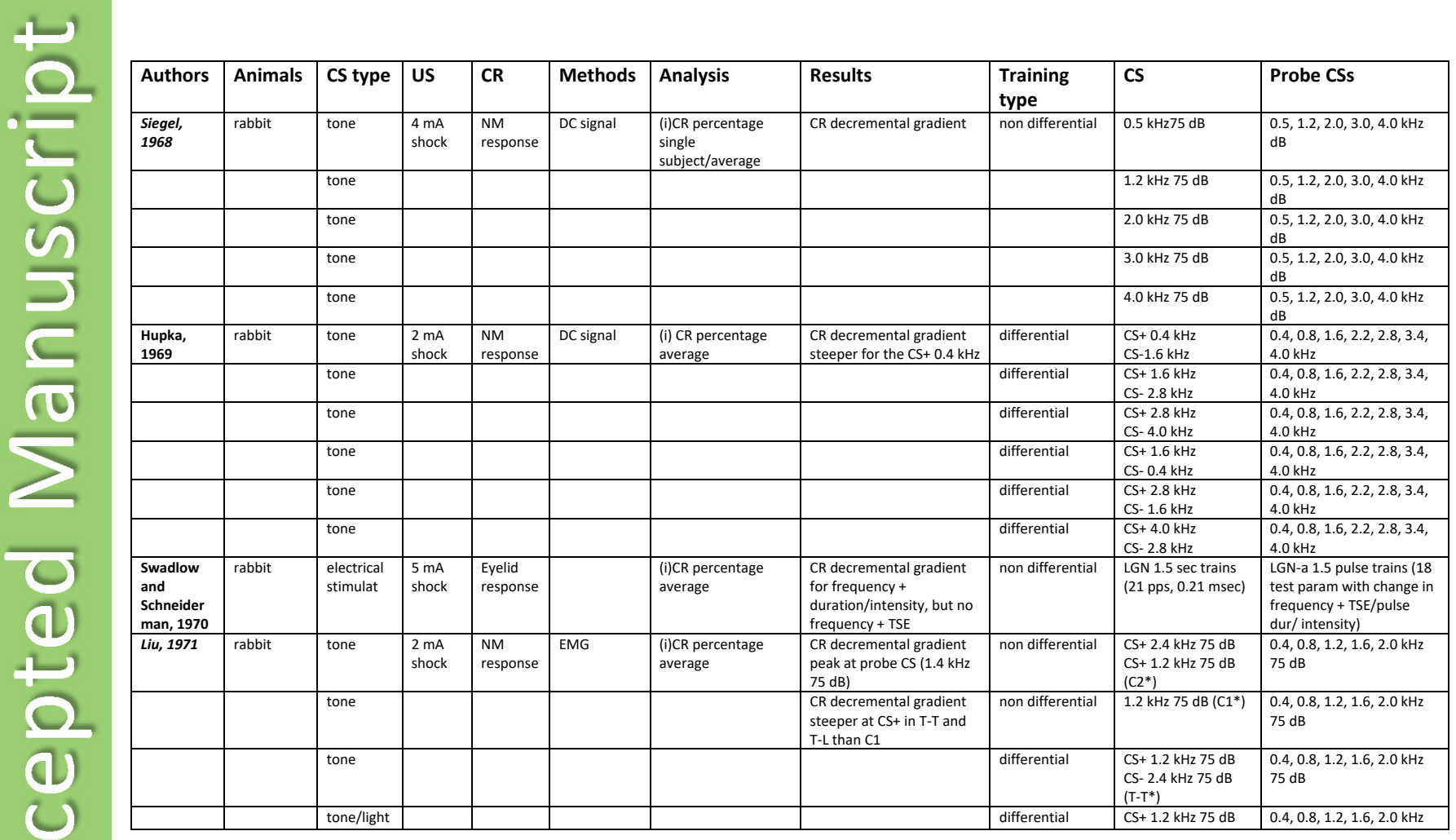




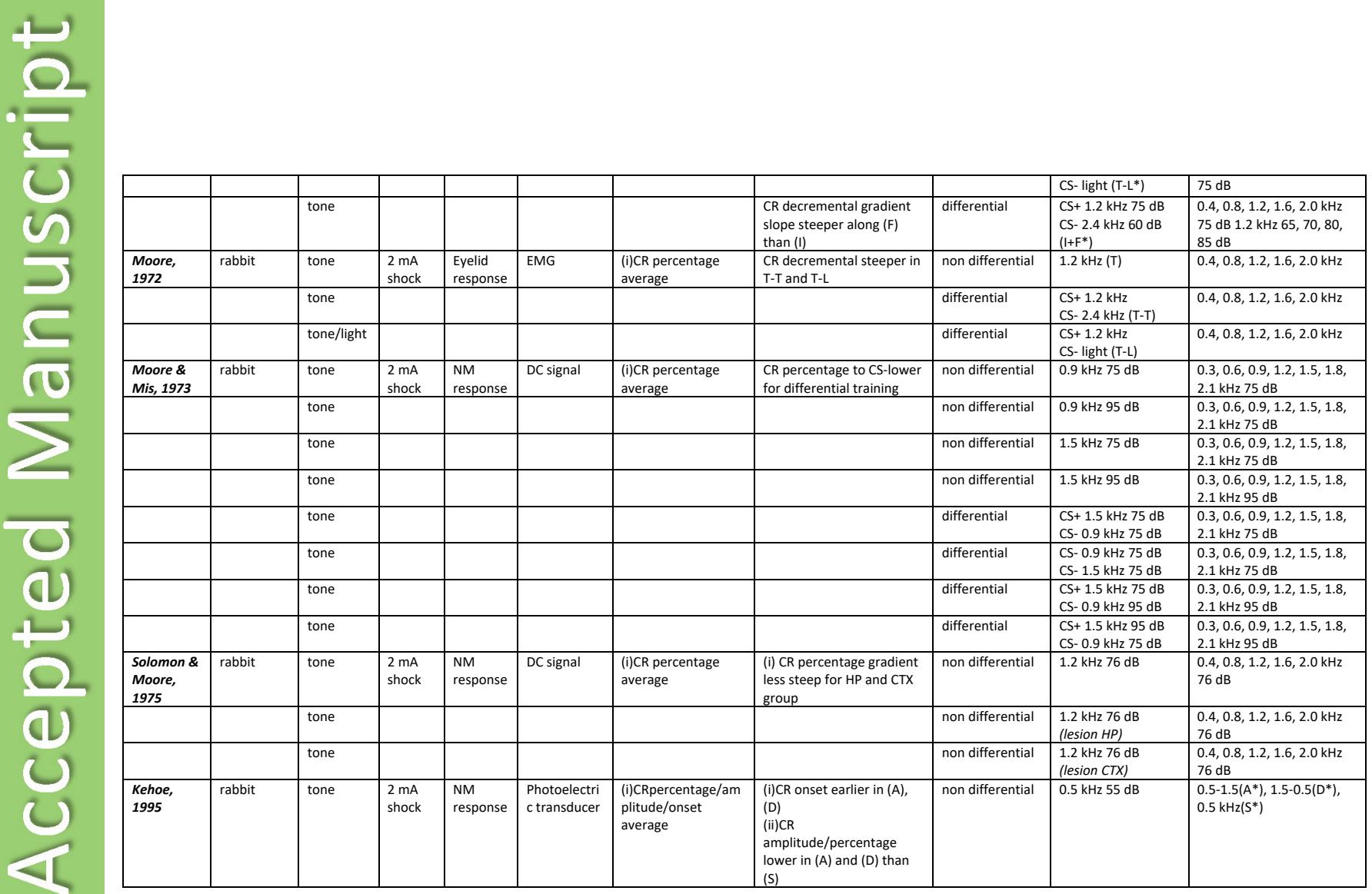




\begin{tabular}{|c|c|c|c|c|c|c|c|c|c|c|}
\hline & & tone & & & & & & \begin{tabular}{|l|} 
non differential \\
\end{tabular} & $1.0 \mathrm{kHz} 55 \mathrm{~dB}$ & $0.5-1.5,1.5-0.5,1.0 \mathrm{kHz}$ \\
\hline & & tone & & & & & & non differential & $1.5 \mathrm{kHz} 55 \mathrm{~dB}$ & $0.5-1.5,1.5-0.5,1.0 \mathrm{kHz}$ \\
\hline & & tone & & & & & $\begin{array}{l}\text { (i)CR onset earlier in (A), } \\
\text { (D) }\end{array}$ & non differential & $60 \mathrm{~dB}$ & $60-90 \mathrm{~dB}, 90-60 \mathrm{~dB}, 60 \mathrm{~dB}$ \\
\hline & & tone & & & & & & \begin{tabular}{|l|} 
non differential \\
\end{tabular} & $75 \mathrm{~dB}$ & $60-90 \mathrm{~dB}, 90-60 \mathrm{~dB}, 75 \mathrm{~dB}$ \\
\hline & & tone & & & & & & non differential & $90 \mathrm{~dB}$ & $60-90 \mathrm{~dB}, 90-60 \mathrm{~dB}, 90 \mathrm{~dB}$ \\
\hline & & tone & & & & & $\begin{array}{l}\text { (i)CR decremental gradient } \\
\text { likelihood/amplitude (ii) } \\
\text { CR onset unchanged }\end{array}$ & non differential & $50 \mathrm{~ms}$ & $50,400,800,1600 \mathrm{~ms}$ \\
\hline & & tone & & & & & & non differential & $400 \mathrm{~ms}$ & $50,400,800,1600 \mathrm{~ms}$ \\
\hline & & tone & & & & & & non differential & $800 \mathrm{~ms}$ & $50,400,800,1600 \mathrm{~ms}$ \\
\hline \multirow[t]{2}{*}{$\begin{array}{l}\text { Svennson, } \\
1997\end{array}$} & ferrets & $\begin{array}{l}\text { electric } \\
\text { stimulat }\end{array}$ & $\begin{array}{l}3 \mathrm{~mA} \\
\text { shock }\end{array}$ & $\begin{array}{l}\text { Eyelid } \\
\text { response }\end{array}$ & EMG & $\begin{array}{l}\text { (i)CR } \\
\text { onset/peaktime } \\
\text { average }\end{array}$ & $\begin{array}{l}\text { (i)CR onset/peaktime } \\
\text { earlier }\end{array}$ & non differential & $\begin{array}{l}\text { Left FL* } 300 \mathrm{~ms} 50 \\
\mathrm{~Hz} 1 \mathrm{~mA}\end{array}$ & Left FL $300 \mathrm{~ms} 50 \mathrm{~Hz} 2 \mathrm{~mA}$ \\
\hline & & $\begin{array}{l}\text { electric } \\
\text { stimulat }\end{array}$ & & & & & & non differential & MCP* $0.1 \mathrm{~ms} 50 \mathrm{~Hz}$ & MCP $0.1 \mathrm{~ms} 100 \mathrm{~Hz}$ \\
\hline $\begin{array}{l}\text { Garcia \& } \\
\text { Mauk, } \\
2003\end{array}$ & rabbit & tone & $\begin{array}{l}4 \mathrm{~mA} \\
\text { shock }\end{array}$ & $\begin{array}{l}\text { (i)NM } \\
\text { response } \\
\text { (ii) eyelid } \\
\text { response }\end{array}$ & $\begin{array}{l}\text { (i) infrared } \\
\text { LED (ii) } \\
\text { photoelectri } \\
\text { c transucer }\end{array}$ & $\begin{array}{l}\text { (i)CR } \\
\text { percentage/amplitu } \\
\text { de/onset/peaktime } \\
\text { average }\end{array}$ & $\begin{array}{l}\text { (i)CR } \\
\text { percentage/amplitude } \\
\text { decremental gradient } \\
\text { (ii)CR onset/peaktime } \\
\text { increment }\end{array}$ & non differential & $1.0 \mathrm{kHz} 75 \mathrm{~dB}$ & $\begin{array}{l}\text { 1.0, 1.26, 1.59, 2.0, 2.52, } \\
3.17,4.0,5.04 \mathrm{kHz} 75 \mathrm{~dB}\end{array}$ \\
\hline \multirow[t]{5}{*}{$\begin{array}{l}\text { Ohyama, } \\
2003\end{array}$} & rabbit & tone & $\begin{array}{l}0.8-2.5 \\
\mathrm{~mA} \\
\text { shock }\end{array}$ & $\begin{array}{l}\text { eyelid } \\
\text { response }\end{array}$ & infrared LED & $\begin{array}{l}\text { (i)CR/SLR } \\
\text { percentage/ } \\
\text { amplitude average }\end{array}$ & $\begin{array}{l}\text { (i)SLR/CR decremental } \\
\text { gradient (excl light) (ii)CR } \\
\text { amplitude unchanged }\end{array}$ & non differential & $1.0 \mathrm{kHz} 85 \mathrm{~dB}$ & $\begin{array}{l}\text { 1.0, 1.85, 3.55, 6.1, } 9.585 \\
d B \text {, light }\end{array}$ \\
\hline & & tone & & & & & $\begin{array}{l}\text { (I)SLR/CR amplitude } \\
\text { decremental gradient }\end{array}$ & non differential & $\begin{array}{l}1.0 \mathrm{kHz} 85 \mathrm{~dB} \\
\left(P C X^{*}\right) \text { cerebellar } \\
\text { cortex }\end{array}$ & $\begin{array}{l}\text { 1.0, 1.85, 3.55, 6.1, } 9.585 \\
d B, \text { light }\end{array}$ \\
\hline & & tone & & & & & $\begin{array}{l}\text { (i)SLR/CR decremental } \\
\text { gradient } \\
\text { (excl light) (ii)CR amplitude } \\
\text { unchanged }\end{array}$ & non differential & $9.5 \mathrm{kHz} 85 \mathrm{~dB}$ & $\begin{array}{l}\text { 1.0, 1.85, 3.55, 6.1, } 9.585 \\
d B \text {, light }\end{array}$ \\
\hline & & tone & & & & & $\begin{array}{l}\text { (I)SLR/CR amplitude } \\
\text { decremental gradient }\end{array}$ & non differential & $\begin{array}{l}1.0 \mathrm{kHz} 85 \mathrm{~dB}(P C X) \\
\text { cerebellar cortex }\end{array}$ & $\begin{array}{l}\text { 1.0, 1.85, 3.55, 6.1, } 9.585 \\
d B, \text { ligh }\end{array}$ \\
\hline & & light & & & & & (i)SLR/CR light only & non differential & light & $\begin{array}{l}\text { 1.0, 1.85, 3.55, 6.1, } 9.585 \\
d B \text {, light }\end{array}$ \\
\hline \multirow[t]{2}{*}{$\begin{array}{l}\text { Svennson, } \\
2009\end{array}$} & ferrets & $\begin{array}{l}\text { electrical } \\
\text { stimulat }\end{array}$ & $\begin{array}{l}3 \mathrm{~mA} \\
\text { shock }\end{array}$ & $\begin{array}{l}\text { Eyelid } \\
\text { response }\end{array}$ & EMG & $\begin{array}{l}\text { (i) SS suppression } \\
\text { single PCs }\end{array}$ & $\begin{array}{l}\text { (i) SS* suppression earlier } \\
\text { in PCs (ii) PCs fire freq } \\
\text { unchanged }\end{array}$ & non differential & $\begin{array}{l}\text { FL } 0.5 \mathrm{kHz} 300 \mathrm{~ms} \\
1 \mathrm{~mA} \text { pulse train }\end{array}$ & $\begin{array}{l}\text { FL } 0.5 \mathrm{kHz} 300 \mathrm{~ms} 2 \mathrm{~mA} \\
\text { pulse train }\end{array}$ \\
\hline & & electrical & CF 0.50 & Eyelid & EMG & (i) SS suppression & (i)SS suppression earlier in & \begin{tabular}{|l|} 
non differential \\
\end{tabular} & MF* 0.5 kHz 400- & MF $1.0 \mathrm{kHz} 400-800 \mathrm{~ms}$ \\
\hline
\end{tabular}




\begin{tabular}{|c|c|c|c|c|c|c|c|c|c|c|}
\hline & & stimulat & $\begin{array}{l}\mathrm{kHz} 10 \\
\mathrm{~ms}(\mathrm{x} 2)\end{array}$ & response & & single PCs & PCs & & $800 \mathrm{~ms}$ pulse train & pulse train \\
\hline $\begin{array}{l}\text { Khilkevich, } \\
2018\end{array}$ & rabbit & tone & $\begin{array}{l}1-3 \mathrm{~mA} \\
\text { shock }\end{array}$ & $\begin{array}{l}\text { eyelid } \\
\text { response }\end{array}$ & infrared LED & $\begin{array}{l}\text { (i)CR } \\
\text { percentage/amplitu } \\
\text { de average }\end{array}$ & $\begin{array}{l}\text { (i) CR decremental } \\
\text { gradient } \\
\text { (ii) CR amplitude } \\
\text { unchanged }\end{array}$ & non differential & $\begin{array}{l}1.0 \mathrm{kHz} 75 \mathrm{~dB} 500 \\
\mathrm{~ms}\end{array}$ & $\begin{array}{l}1.0 \mathrm{kHz} 75 \mathrm{~dB} 50,100, \\
150,200,250,300,350, \\
400,450 \mathrm{~ms}\end{array}$ \\
\hline & & $\begin{array}{l}\text { electrical } \\
\text { stimulat }\end{array}$ & & & & & & non differential & $\begin{array}{l}\text { MF pulse train } 100 \\
\mathrm{~Hz} 100-150 \mathrm{~mA}\end{array}$ & $\begin{array}{l}\text { MF pulse train 90, 80, 70, } \\
60,50 \mathrm{~Hz} 100-150 \mathrm{~mA}\end{array}$ \\
\hline & & $\begin{array}{l}\text { electrical } \\
\text { stimulat }\end{array}$ & & & & & & non differential & $\begin{array}{l}\text { MF pulse train } 100 \\
\mathrm{~Hz} 100-150 \mathrm{~mA}\end{array}$ & $\begin{array}{l}\text { MF (competing) pulse } \\
\text { train } 100 \mathrm{~Hz} 100-150 \mathrm{~mA}\end{array}$ \\
\hline
\end{tabular}

1108

1109

1110

\begin{tabular}{ll} 
& Abbreviations \\
\hline C1 & 1 CS (tone/light) \\
C2 & 2 CSs (reinforced tone) \\
T & 1 CS tone \\
T-T & Tone-Tone \\
T-L & Tone-Light \\
F+1 & Frequency + intensity \\
A & Ascending tone \\
D & Descending tone \\
S & Steady tone \\
FL & Forelimb \\
MCP & Middle cerebellar peduncle \\
MF & Mossy Fibers \\
PCX & Picrotoxin \\
TSE & Total stimulus energy \\
LGN & Lateral geniculate nucleus \\
HP & Hippocampus \\
CTX & Cortex
\end{tabular}

1111

1112 
Figure 1

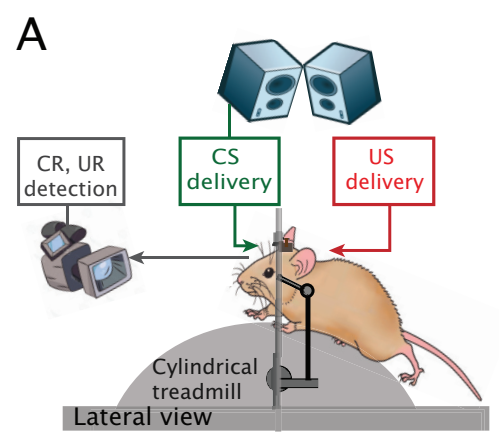

B Acquisition Training: Day 1-10

US only: $10 \%$ CS-US paired: $80 \%$ CS only: $10 \%$

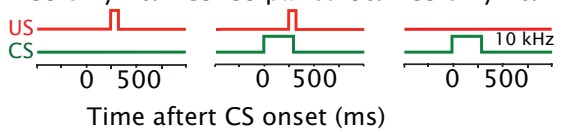

Generalization Test: Day 11-17

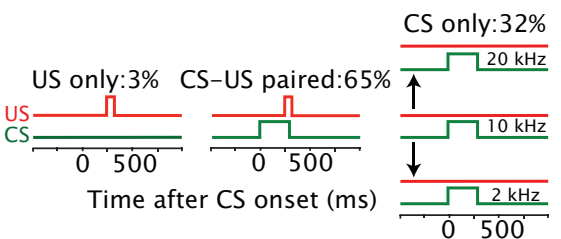

C Acquisition Training
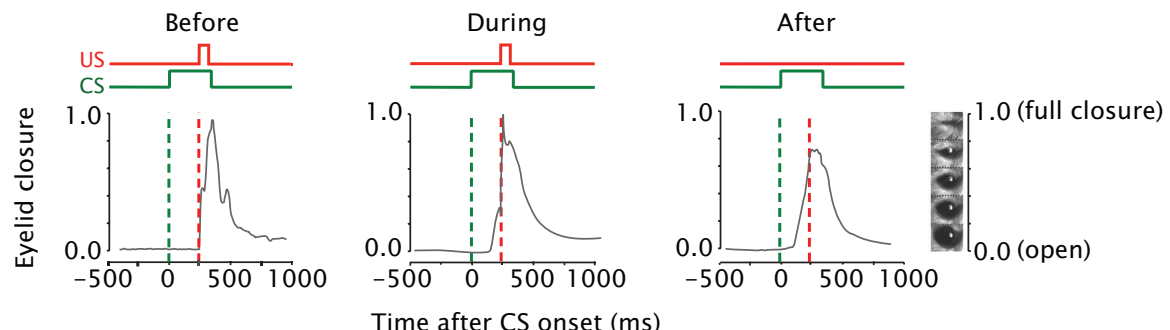
Figure 2

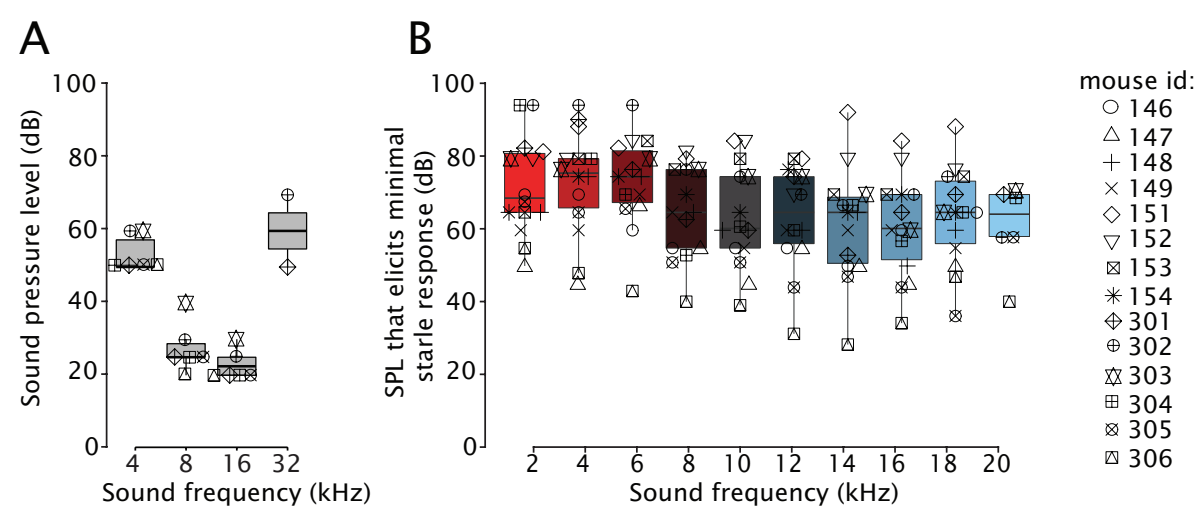


Figure 3
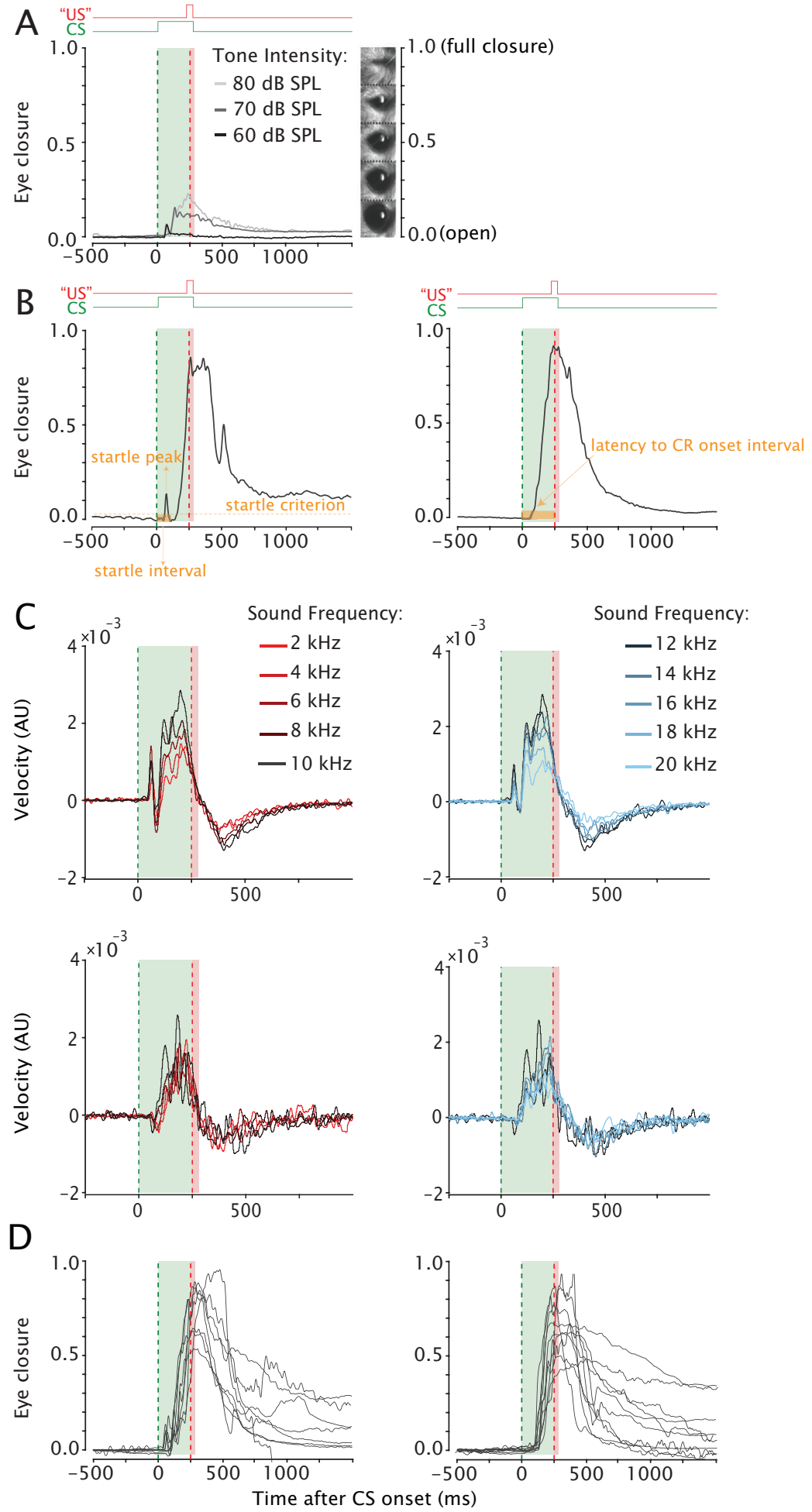
Figure 4
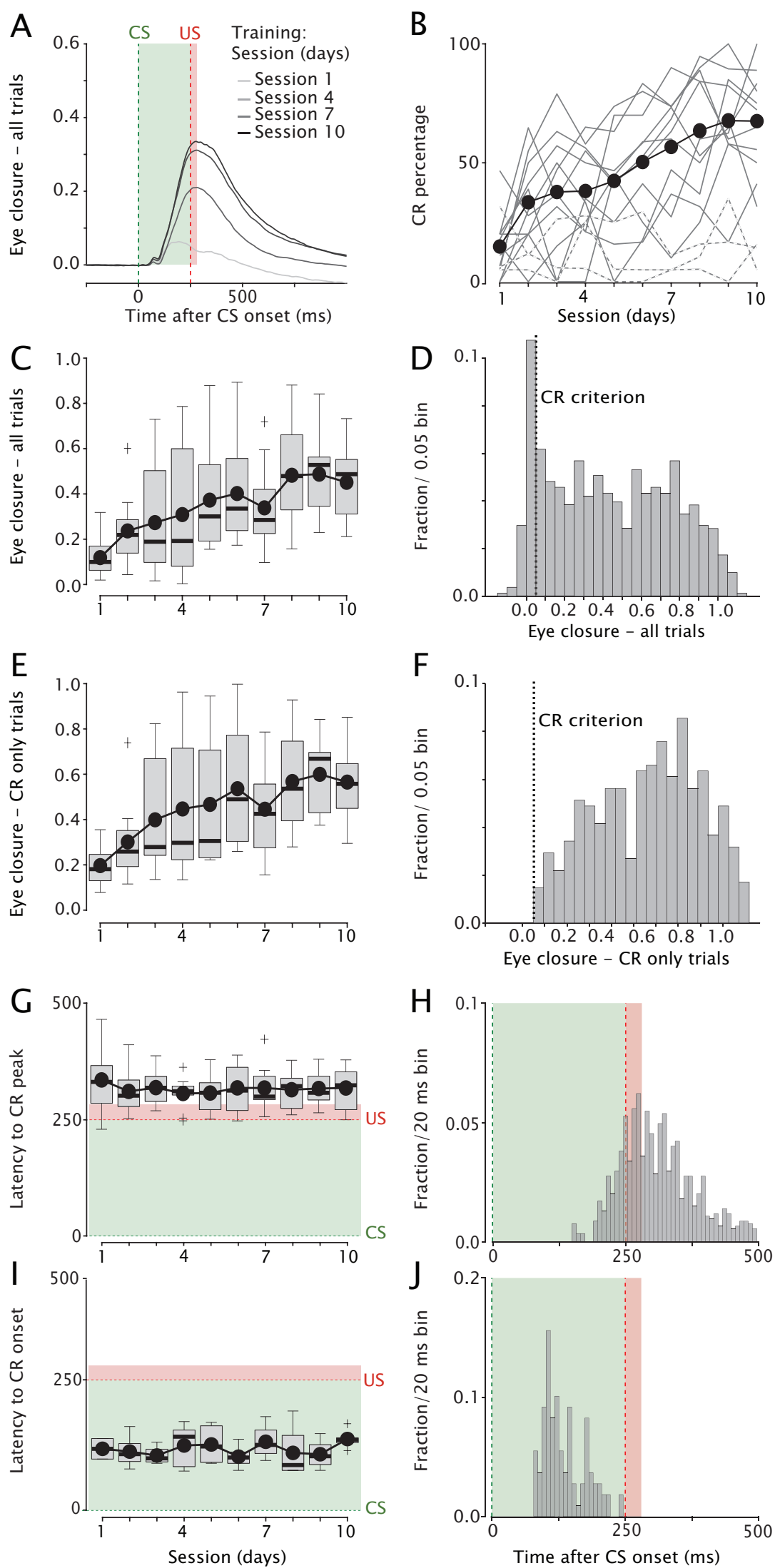
Figure 5

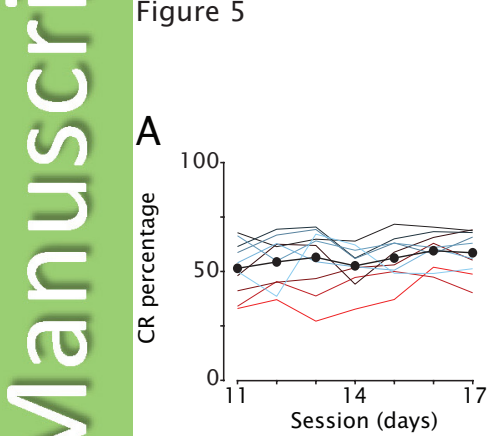

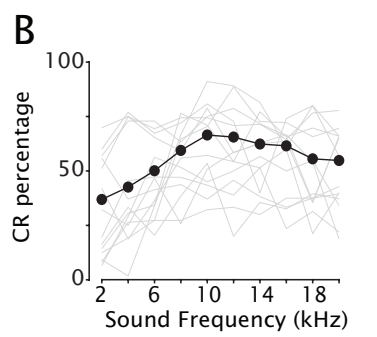
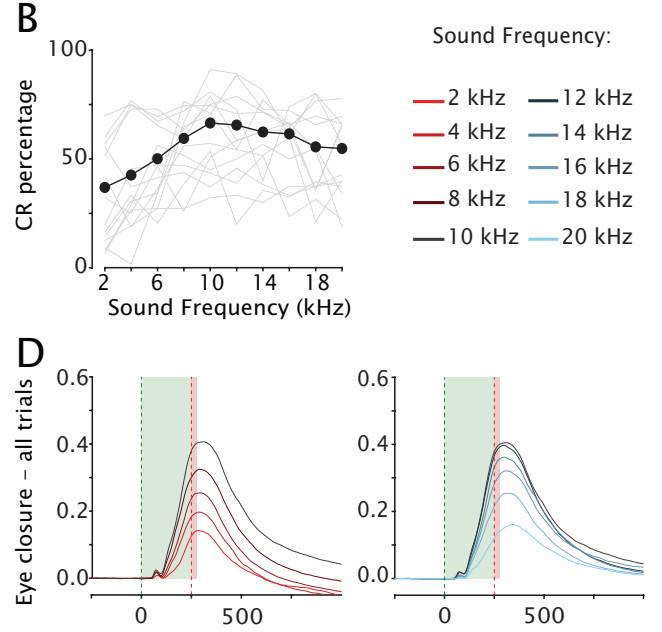

G

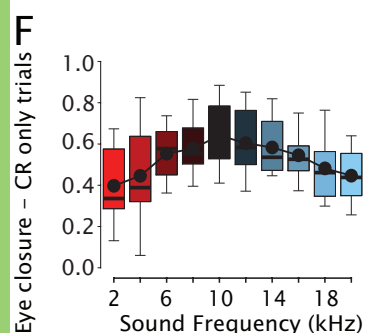

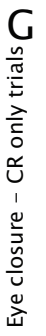
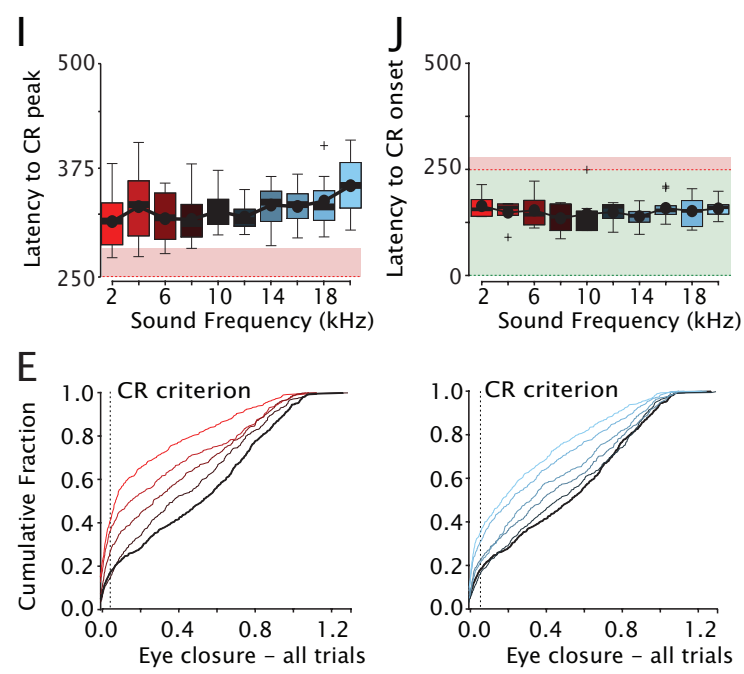

$\mathrm{H}$

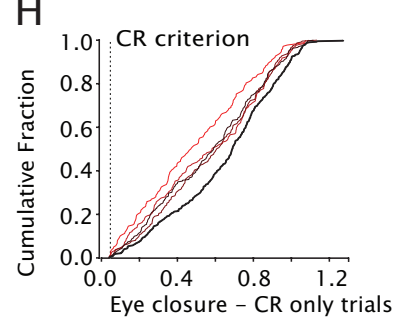

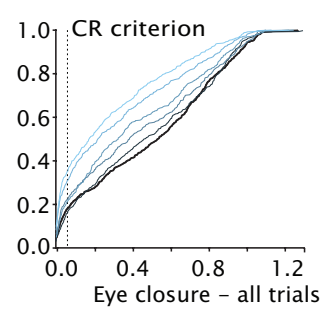

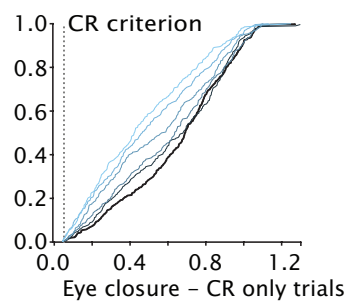


Figure 6

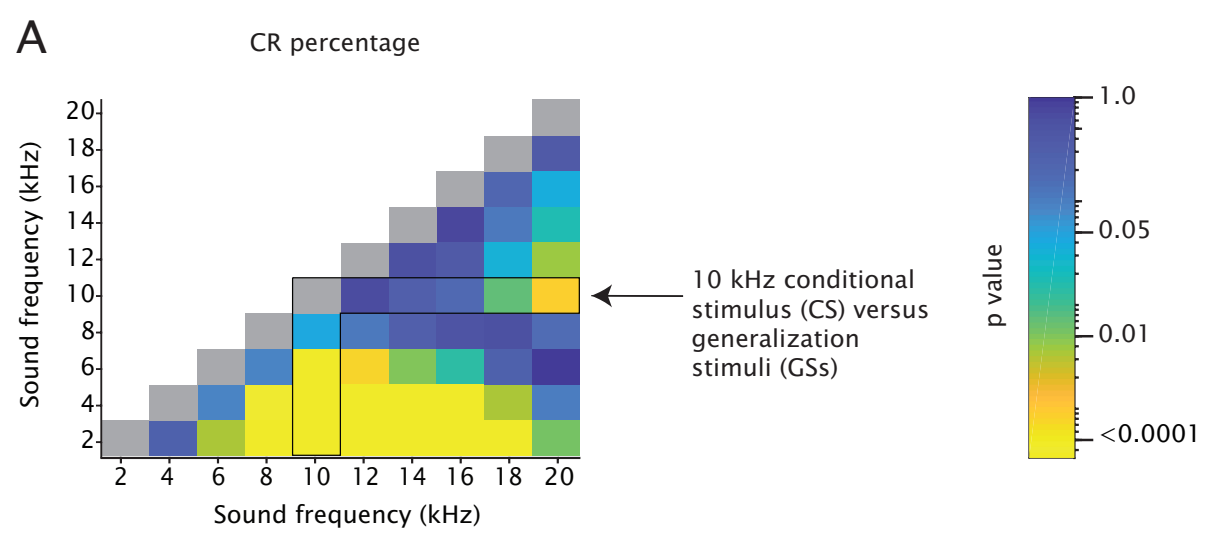

B Eye closure - all trials

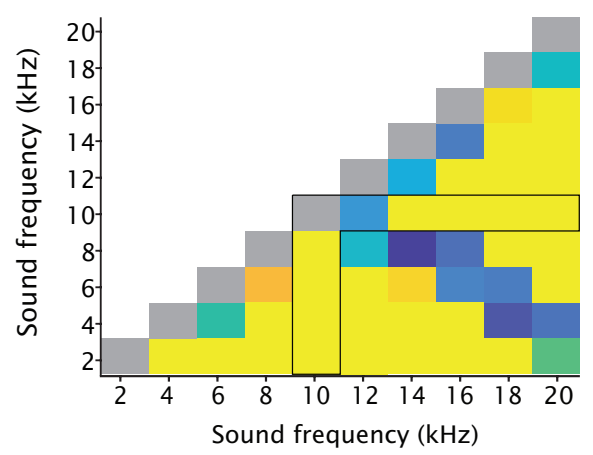

D Latency to CR peak

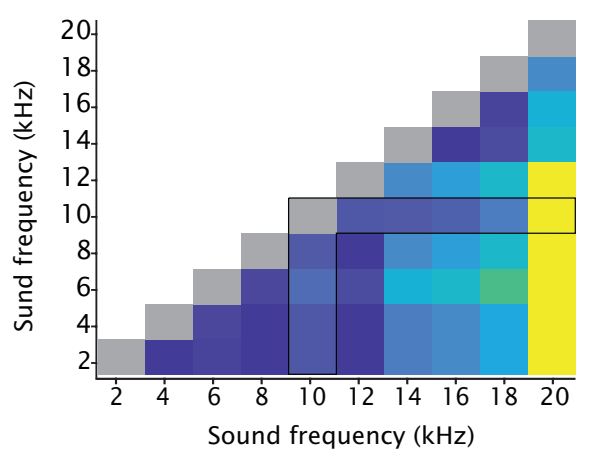

C Eye closure - CR only trials

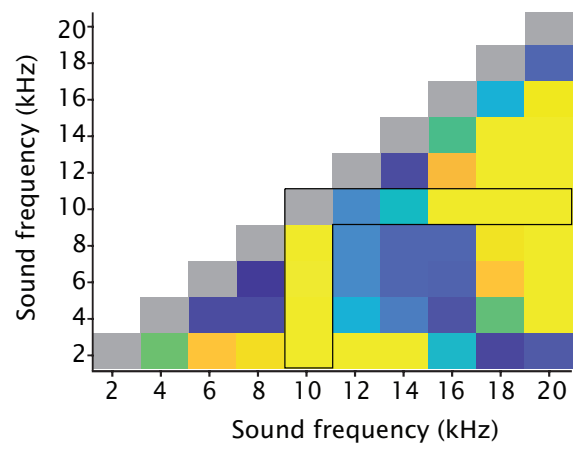

E

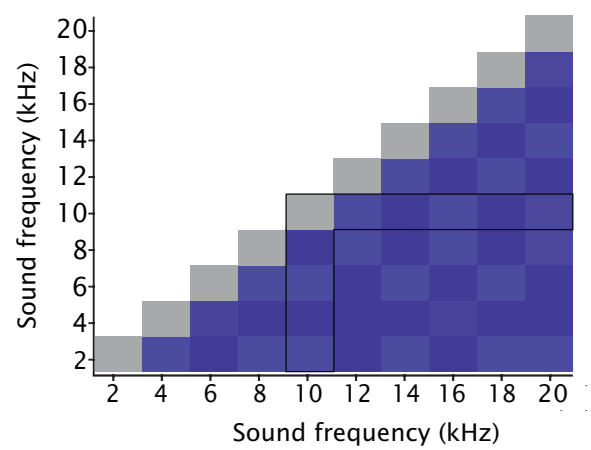




\section{Figure 7}

A Eye closure - all trials CR criterion: 0.05

B Eye closure - CR only trials CR criterion: 0.05
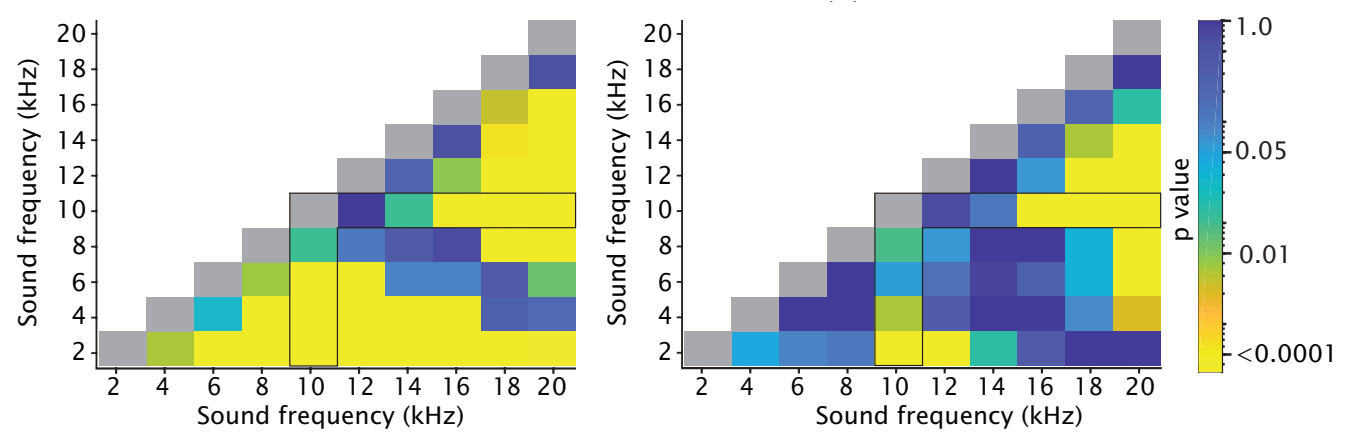

(1)

()

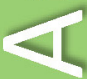

(2)

는

(a)

(4) 
Figure 8

A

Eye closure - all trials
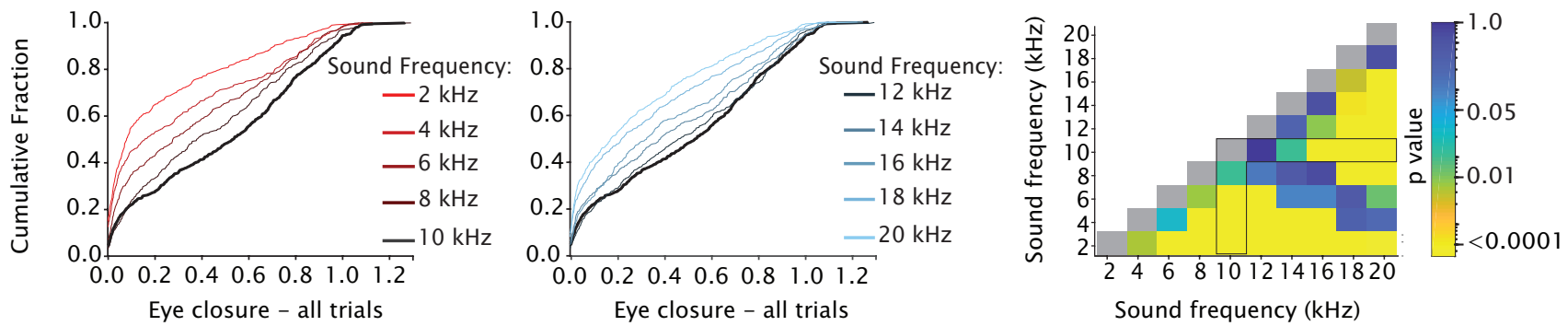

B

Eye closure - CR only trials using a CR criterion of 0.10
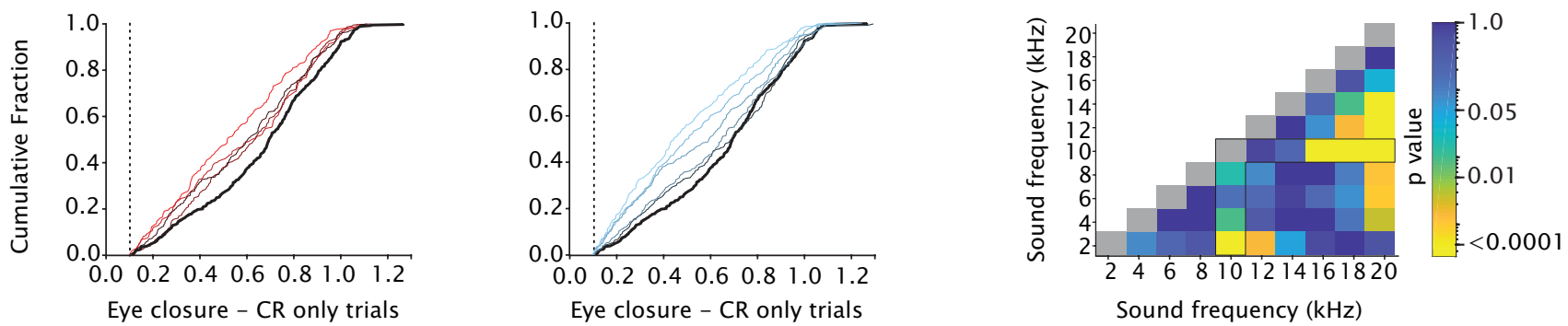

C

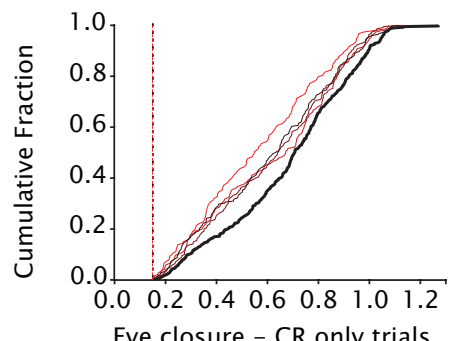

D

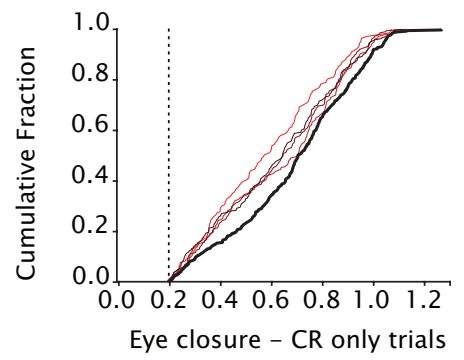

Eye closure - CR only trials using a CR criterion of 0.15

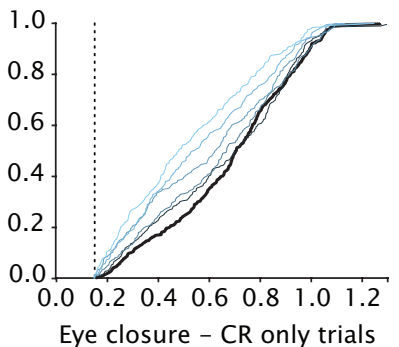

Eye closure - CR only trials

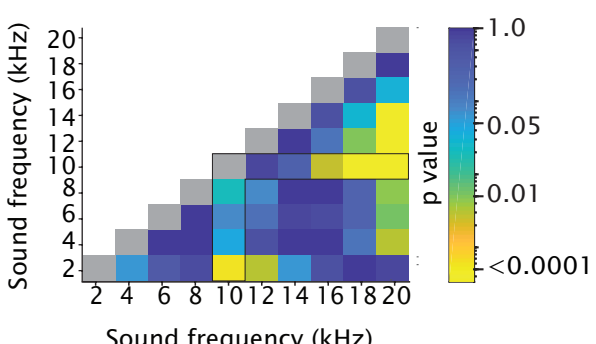

Eye closure - CR only trials using a CR criterion of 0.20
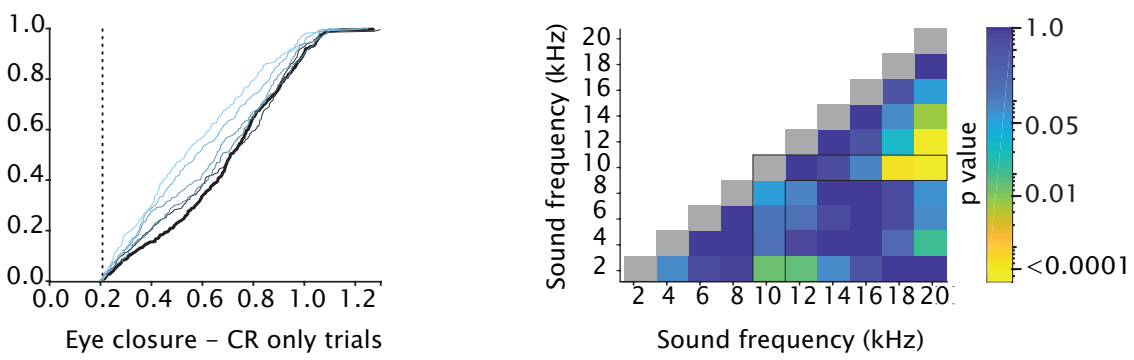

$\mathrm{E}$

Eye closure - CR only trials using a CR criterion of 0.45
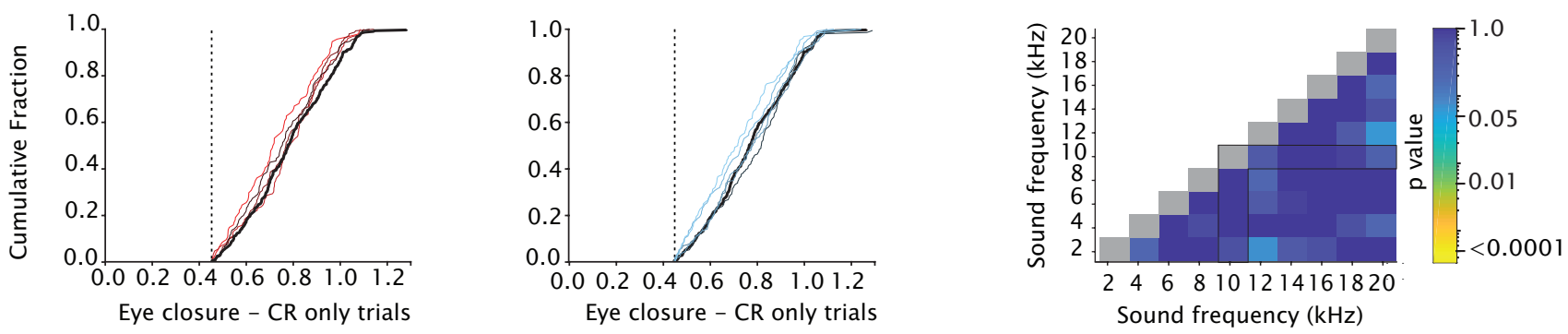
Figure 9
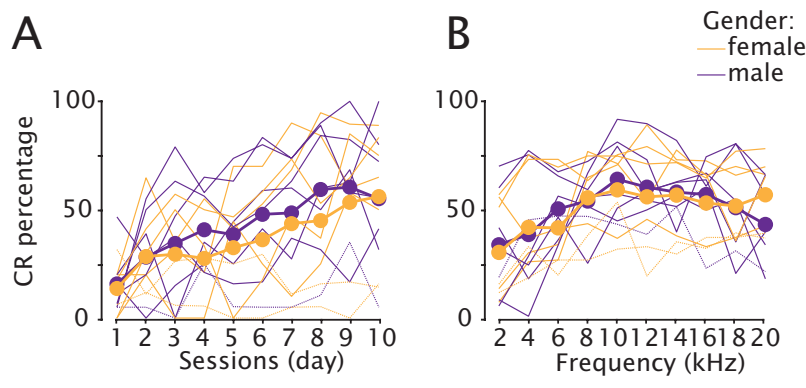

(d)

(U)

(u)

$<$

(อ)

는

()

(1)

(1) 